\title{
FORTIFICACIONES Y ARQUITECTURA MILITAR DE LAS ISLAS CHAFARINAS DURANTE EL SIGLO XIX
}

\author{
ANTONIO BRAVO NIETO \\ Profesor-tutor UNED \\ Instituto de Cultura Mediterránea
}

\section{LOS ANTECEDENTESY LA OCUPACIÓN}

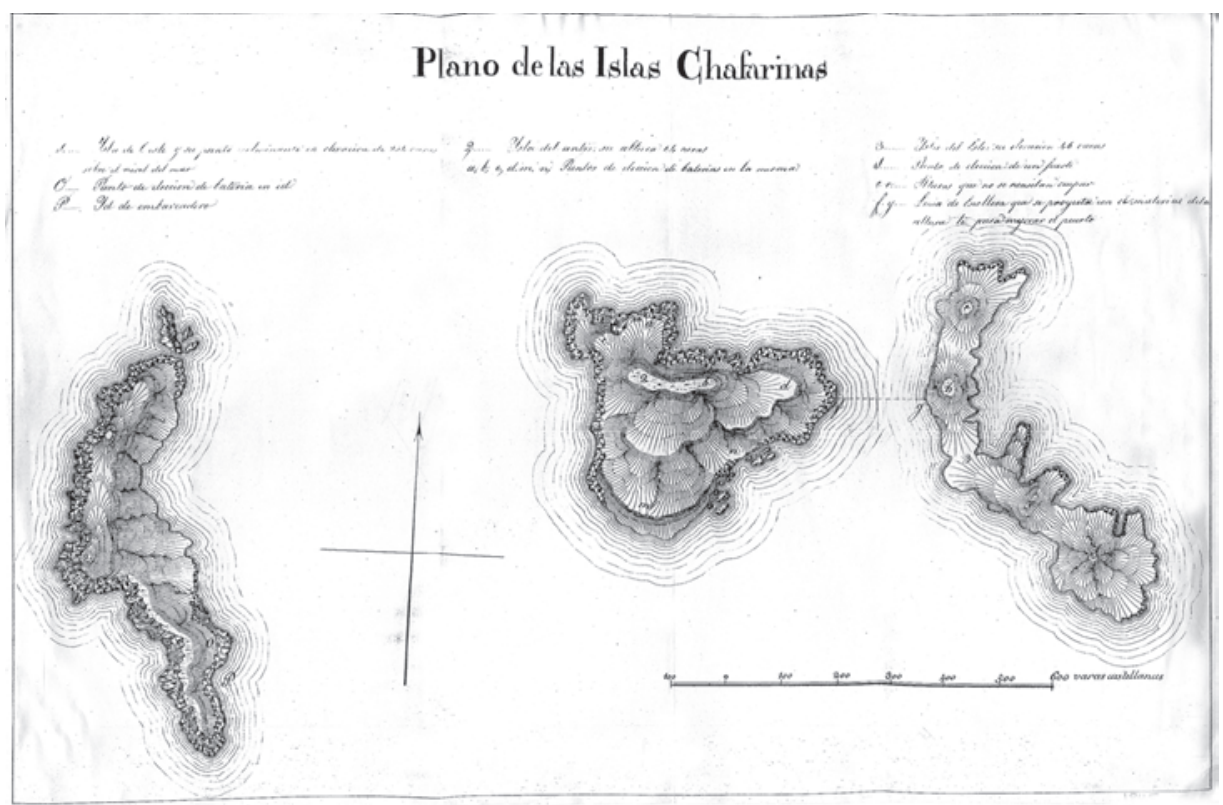

1845. Plano de las islas Chafarinas con propuesta de fortificación.

La ocupación de las islas Chafarinas dependió de su posible fortificación. Por esta razón podemos considerar como su antecedente más inmedia to la visita que el brigadier de ingenieros Miguel de Santillana y Díez realiza en 1845, con la misión de redactar un informe sobre las obras de defensa que se debían acometer en caso de que fuesen ocupadas ${ }^{1}$. Santillana proyectaba en la isla del oeste (Conge-

\footnotetext{
1 Visita del brigadier Miguel Santillana en 1845 (AGMM) Fondo África, R 823.6.
} 
so) la construcción de una batería, así como un pequeño embarcader o. En la del este (Rey) se debía elegir un punto para ubicar un fuer te, y aconsejaba construir una escollera para unir esta isla con la central (Isabel II)formando un puerto natural. Finalmente, la isla central debía albergar las pincipales defensas del ardhipiélago, señalándose puntos estra tégicos para situar seis ba terías. En este proyecto se marcaban los objetivos generales que posteriormente determinan la fortificación del archipiélago: la elección de la isla del centr o como la más apta para situar la población, el necesario flanqueo artillero entre las tres islas y la necesidad de construir varios espigones que formaran un puerto natural en su rada.

Dos años después, el gobier no acomete definitivamente la operación y comienza a aplicarse su primer plan de defensa. De todas las informaciones que se barajaban sobre las islas, una de ellas tendría consecuencias miy negativas para el futuro: se pensaba er róneamente que podría encontrar se agua potable excavando pozos.

Todo el proceso de ocupación que se materializaría en los primeros días de enero de 1848 ya ha sido estudiado en su capítulo corespondiente, pero queremos señalar aquí que en la acción se utilizar on diversos barcos de guer ra que darían posteriormente sus nombres a diferentes obras de fortificación de las islas, destacando dos vapores, el Piles y el Vulcano, el bergantín Isabel I ${ }^{2}$ y el místico Flecha.

Los ingenieros militares encargados de dirigir todos los trabajos de fortificación en estos primeros momentos fueron los comandantes de ingenieros de Málaga y Melilla: teniente coronel Juan de Irigoyen, comandante Martin Justo deVillota y teniente Feliciano Valdivieso y Alcázar, aunque los pro yectos y la planificación tuvo que ser realizada obviamente con antelación. Los elementos y útiles para las fábricas, por su parte, procedían del parque de ingenieros de Ceuta ${ }^{3}$, mientras que los trabajos fueron ejecutados principalmente por confinados, por los efectivos de ingenieros y por toda la guarnición disponible ${ }^{4}$.

\footnotetext{
${ }^{2}$ Se proyectaría posteriormente una batería con el nombre de este barco, Isabel I. Sin embargo esta batería sería denominada en varias ocasiones con el nombre de Isabel II, sobre todo a finales del siglo XIX.

${ }^{3}$ Todas las referencias en: Memoria, Málaga 4 de febrero de 1848, José del Hoyo, Coronel Jefe de E.M. Resumen histórico de la expedición y ocupación militar de las islas Chafrinas, SGE Caja 6, nº 5. Ver el primer plan de obras en Proyecto de Fortificación de las islas Chafarinas, AGMM. R823.1.

${ }^{4}$ Los efectivos embarcados consistieron en un escuadrón de caballería, un batallón de infantería y un batallón del Regimiento Fijo de Ceuta, así como efectivos de artillería (una batería de montaña) y una compañía del regimiento de ingenieros.
} 


\section{El primer plan de defensa}

Los primeros trabajos defensivos estuvieron encaminados en una doble dirección, por un lado realizar las principales fortificaciones en la isla de Isabel II que permitieran repeler cualquier ataque externo, y por otr o construir los edificios para alojar a la guarnición y cubrir sus principales necesidades. Así "se procedió a construir explanadas, barracones para cuarteles, cuerpos de guardia, almacenes de pólvora y víveres y todo lo demás perteneciente a ingenieros y artillería”.

Las baterías se construyeron a un ritmo vertiginoso, de forma que en cuanto las piezas artilleras pudieron descargarse de los barcos, se fueron instalando en las ubicaciones previstas. Las obras ejecutadas en estos pr imeros días fueron las siguientes: al norte de la isla un reducto-batería llamado de la Conquista, en forma de hexágono irregular, en el que provisionalmente se montarían seis piezas de gueso calibre; otro situado al sur que se llamó Vulcano, en forma de rediente de ángulos achaflanados y que se debía artillar con otras seis piezas y finalmente, en el flanco este, un revellín denominado Piles, con cuatro piezas artilleras.

Durante el mismo mes de enero, se decidió el artillado definitivo de la isla de Isabel II, que el general Francisco Ser rano, duque de la Torre, quería que constase de 22 piezas de gran calibre que debían distribuirse por todas sus defensas. Así en los fuertes ya casi concluidos como el reducto de la Conquista (cuatro piezas de a 16 y un mortero de a 9), Batería Vulcano (la misma dotación), Batería del Piles (dos cañones de a 12, y obuses de a 7). Mientras que los otr os dos cañones de a 12 y dos ob uses de a 7, con los cua tro cañones que faltaban por llegar todavía, serían colocados en las bđerías que se estaban trazando en la pate sur de la isla, la batería llamada Isabel I y otra que llevaría el nombre de Flecha, completando así el nombre de los cinco barcos de guerra principales que llevaron a cabo la ocupación.

Por su par te, las otras dos islas $\mathrm{r}$ ecibían una atención menor y se había proyectado el montaje de dos blockhaus ${ }^{5}$ (que llegaron desde Cádiz el día 15 de enero) uno en Rey y otro en Congreso, aunque ambos debían complementarse con la construcción de un reducto que debía contar con piezas artilleras para que la isla de Rey cruzara fuegos con la batería de Piles y la isla de Congreso con las baterías de Isabel I y Vulcano. Sin embargo, no parece que se hicieran las obras

\footnotetext{
${ }^{5}$ Preferimos utilizar la palabra alemana blockhaus, frente a la española blocao debido a que en el siglo XIX se utilizaba el término alemán en la mayor parte de los documentos y literatura.
} 
complementarias ni se artillaran, por lo que los b lockhaus se mantuvieron como Finalmente en la parte más alta de Congreso debía realizarse un garitón para vigía, dotado de hilo telegráfico para dar aviso a la isla principal en momentos de peligro.

En cuanto a los edificios, se construyen en estos días también en la isla principal la casa del Gobemador, cuarteles, hospital y almacén, siguiendo el modelo de una población. Se realizaron en la zona alta por dominar la isla, ser lugar más ventilado y hallar se defendidas entre las ba terías del nor te y sur. Respecto al agua potable, se excavaron infructuosamente varios pozos, pero con decepcionantes resultados al encontrarse siempre agua salobre. Por esta razón comenzó la necesaria construcción de aljibes al resultar el agua potable difícil de traer y con un costo muy elevado. En estos primeros momentos ya se inicia la constr ucción un aljibe, aunque se advertía que la v egetación de la isla podía en venenar el agua de la escorrentía y había que habilitar medios para evitar intoxicaciones.

La misión debía parecer definitivamente cumplida, y en la tarde del día 23, el general Serrano abandonaba la rada, dejando las islas en un estado de defensa mediano y una guar nición compuesta por cua tro compañías del r egimiento de infantería de Navarra, un destacamento artillero de treinta y cinco hombres y cien confinados para los trabajos, siendo su primer gobernador Vicente Ilarduya ${ }^{6}$.

Después de la partida de Serrano, las obras debieron continuar, y gracias a un informe redactado entre mayo y junio de 1848 conocemos como se fuer on terminando y proyectando otras nuevas ${ }^{7}$. Sin embargo la ma yor parte de las propuestas no llegarían a concretarse en la realidad, como el sistema de flanqueo del archipiélago basado en las baterías que se pensaba construir en las islas laterales. En la isla de Cong reso para complementar al b lockhaus (que contaba con guarnición de un cabo y cuatro soldados) se había proyectado una batería llamada Serrano con seis cañones. En la isla del Re y se proyectaba por su par te una batería de siete cañones, denominada Ros de Olano, pero su blockhaus estaba sin destacamento por no haberse terminado totalmente.

En la isla de Isabel II se desplegaban, como ya hemos visto, las principales obras. La batería de la Conquista disponía de doce piezas que dinigían sus fuegos fijantes al mar (a una supuesta flota enemiga) y rasantes (en el caso de que el enemigo pudiera haber desembarcado en la isla). Isabel I contaba con siete piezas

\footnotetext{
${ }^{6}$ Memoria, Málaga 4 de febrero de 1848, José del Hoyo, Coronel Jefe de E.M. Resumen histór ico de la expedición y ocupación militar de las islas Chafarinas, SGE Caja 6, n 5.

715 de mayo a 6 de junio de 1848. Javier de la Vega.
} 
fijantes al mar. Piles con seis piezas de fuegos rasantes y el Flecha con otras seis piezas, todas de grueso calibre, a barbeta y construidas con sacos de tierra, fosos poco profundos y parapetos bajos.

Por otra parte había que cerrar totalmente el perímetro de Isabel II. Esta isla tiene un perfil escarpado e inaccesible en su mayor parte, pero en las zonas de más fácil acceso era necesario levantar una pequeña muralla de cinco pies (un metro y medio aproximadamente) de espesor, realizada en mampostería y que estaba por entonces en construcción.

También se continuaban otros trabajos como el revestimiento interior del aljibe y un grupo de operarios, bajo la dirección del mayor interino de la plaza, llevaba a cabo un m uelle o desembarcadero que ya estaba en esos meses muy adelantado, echando piedras al mar.

En las obras trabajaban doscientos confinados, una compañía de zapadores y parte de los soldados de la guarnición. Sin embargo y a pesar de las indicaciones que determinaban que las obras fueran permanentes de cal y piedra, la mayor parte consistían en barracones de madera y sólo la casa del gobemador estaba cubierta con teja.

Los trabajos debieron ser muy intensos en estos pr imeros momentos y conocemos algunos de los proyectos que se ejecutaron, firmados en agosto de 1848 por el ingeniero Francisco de Alemany y Gil de Bernabé ${ }^{8}$, aunque de limitados vuelos, como el cuartel de zapadores. A reseñar que en la mayor parte de los proyectos que debían hacer se se tenía que explanar el suelo de $\mathrm{r}$ oca para conseguir superficies planas, por culpa de la pendiente de la isla, al mismo tiempo que se extraía roca para las mismas obras.

\section{El proyecto defensivo de Francisco Alemany ${ }^{9}$}

Sin embargo, el trabajo más interesante de Francisco Alemany, como comandante de la plaza, fue un proyecto general de fortificación de la Isla de Isabel

${ }^{8}$ Planta alzada y perfil del Cuartel de Zapadores proyectado por el teniente coronel capitán del cuerpo D. Francisco de Alemany. Dibujado por el capitán teniente del cuer po D. Juan Francisco de Orduña, 8 de agosto 1848 (AIHCM, Melilla n ${ }^{\circ}$ 417).

${ }^{9}$ Cuerpo de Ingenieros del Ejército. Comandancia de las islas Chaf arinas. Plano de la Isla de Isabel $2^{a}$ levantado por el teniente del cuer po D. Feliciano Valdivieso con la brújula, en el cual v a marcado el pro yecto de fortificación permanente hecho por el capitán D. Francisco de Alemany y dibujado todo por el teniente del cuerpo D. Antonio Torner. Isabel II, 24 de septiembre de 1848. ML-03-14. 
II, aunque desconocemos si planteaba obras en las otras dos islas. La parte de la población construida hasta ese momento obedecía a la adaptación al terreno y a la disposición "como un poblado" que ya encontramos descrita en las primeras memorias: hospital, fragua y panadería, pabellones, barracones varios que servían para almacén, cuartel del presidio, aljibe y dos manzanas con cuarteles en la zona alta, uno de ellos para zapadores.

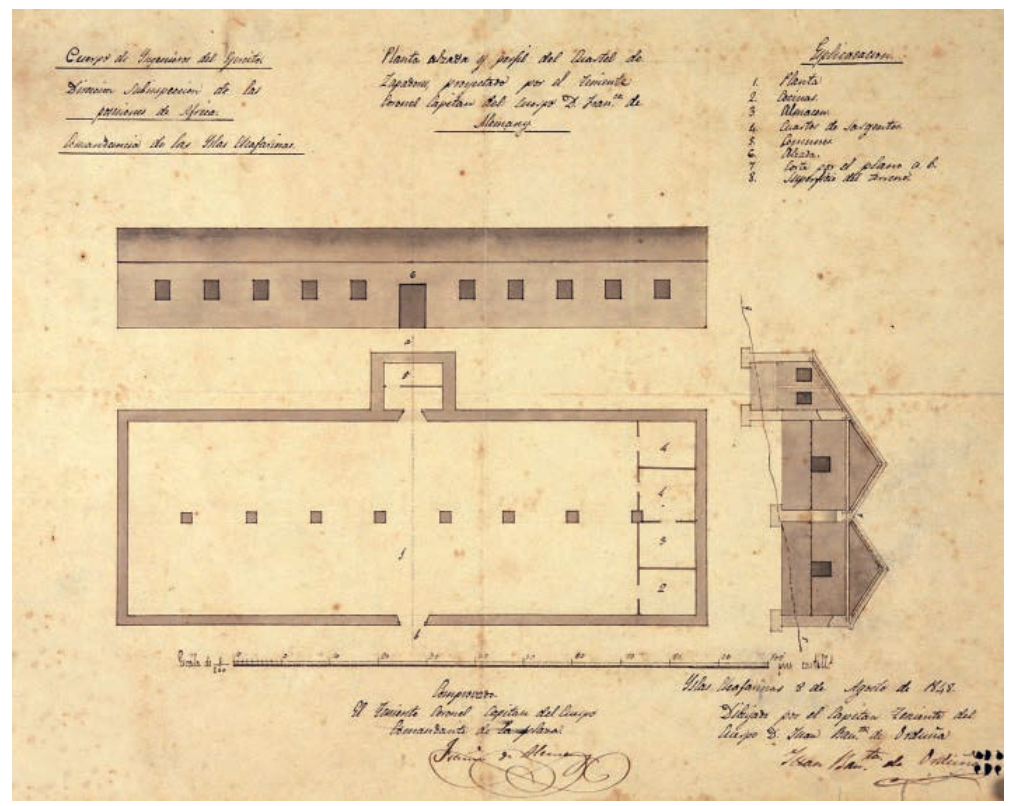

Planta alzada y perfil del Cuartel de Zapadores proyectado por D. Francisco de Alemany. 8 de agosto 1848 (AIMML, Melilla n $\left.{ }^{\circ} 417\right)$.

Alemany no refleja en este plano los fuer tes construidos, proponiendo a su vez otros diferentes. Sin embargo no se señalan las fotificaciones construidas, salvo la muralla de circunvalación, sobre todo en la zona baja donde figura una muralla en cuyo centro se abre la puerta de entrada a la isla, en el mismo sitio donde está ahora. La muralla construida se adapta al terreno y forma diferentes quiebros, pero la reforma plantea un diseño más adaptado a la foma abaluartada. Este detalle revela cierto carácter arcaico al basar las defensas de esta $\mathrm{m}$ uralla más en la preceptiva de un perímetro canónico abaluartado, que en una línea de flanqueos. Por ello, Alemany genera un medio baluar te (llamado Irigoyen), un baluarte completo (Ramón Zarco delValle y un semibaluarte (llamado Plutón), que tenía su arranque al norte en una torre cuadrangular llamada Valdivieso. 


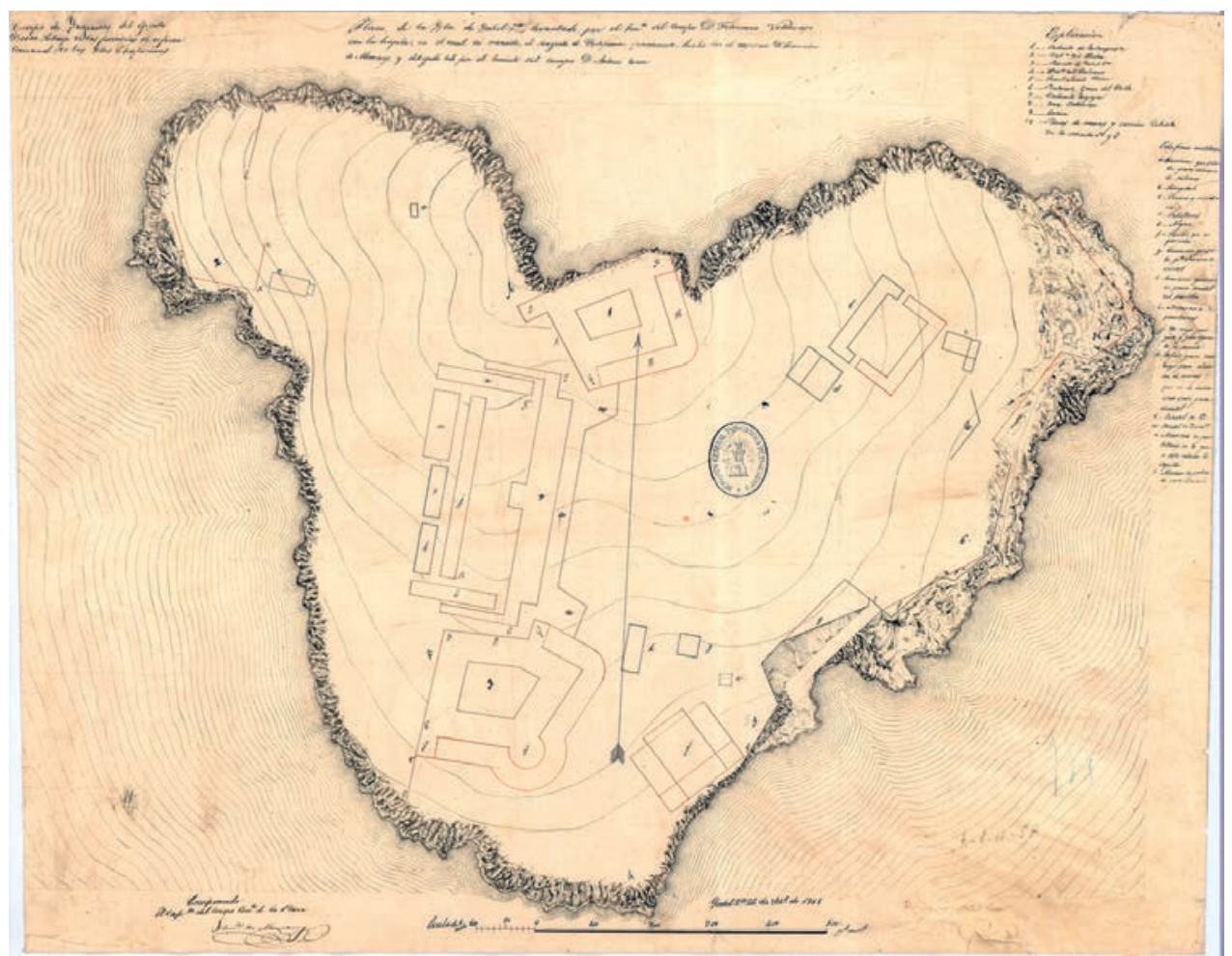

Plano de la Isla de Isabel $2^{a}$ con el proyecto de fortificación permanente hecho por el capitán D. Francisco de Alemany, 24 de septiembre de 1848. IHCM. ML-03-14

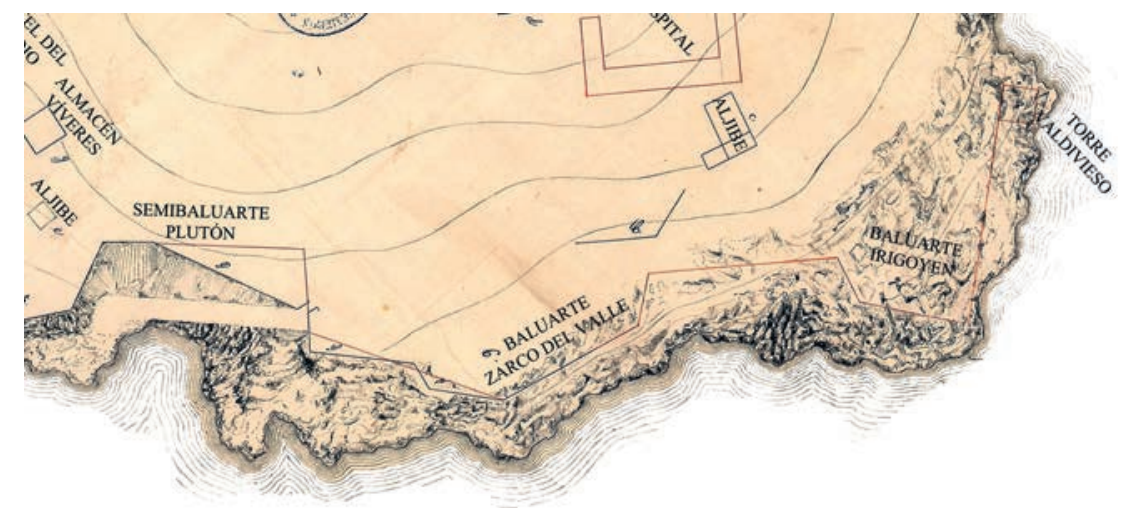

Sector de la muralla en el Plano de la Isla de Isabel $2^{a}$ con el proyecto de fortificación permanente hecho por el capitán D. Francisco de Alemany, 24 de septiembre de 1848. ML-03-14. En negro figura lo que existía y en rojo la propuesta de Alemany. 
Por otra parte, Alemany situaba dos fuertes o baterías en los mismos lugares donde ya estaban construidos el reducto de la Conquista (Nor te) y el de Isabel I (al Sur y que denomina er róneamente Isabel II). Estos fuertes son proyectados con planta cuadrangular o trapezoidal, patio central y son característicos por contar con redientes (cuadrangulares o circulares) en sus ángulos para permitir su flanqueo.
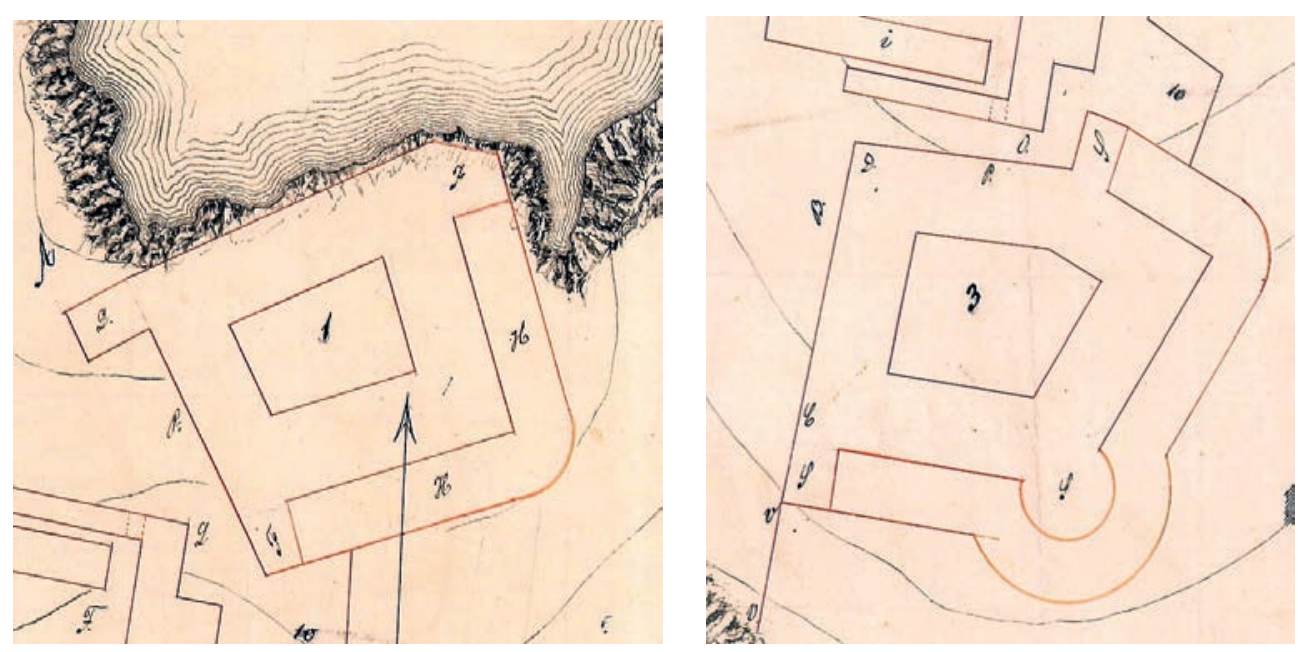

Sector de los fuertes de la Conquista (1) y de Isabel I (3) en el Plano de la Isla de Isabel $2^{a}$ con el proyecto de fortificación permanente hecho por el capitán D. Francisco de Alemany, 24 de septiembre de 1848. ML-03-14

Ambos fuertes contaban con un foso parcial en su fr ente este, estando unidos entre sí por una plaza de armas y camino cubierto.

Con ello se definía un frente fortificado que dividía la isla de Isabel II de Norte a Sur, en una idea defensiva un tanto arcaica. El resto de baterías la formaban al oeste la batería del Flecha y al sur la batería de Vulcano, aunque la batería del Piles parece descartada en el nuevo proyecto.

Dentro del plan de defensa deAlemany se planteaba una larga manzana de pabellones ${ }^{10}$ que también dispondría de alojamiento para el gober nador, el co-

${ }^{10}$ Plantas, Perfil y Alzada de la manzana de pabellones proyectada por el capitán del cuerpo Don Francisco de Alemany y dibujado por el teniente del mismo Don Juan de Orduña. 7 enero 1849. ML-03-15. 
mandante de Artillería, el de Ingenieros y los oficiales de la guamición. Se trataría por tanto del pabellón de mando de las islas a constr uir detrás de la línea defensiva citada y por tanto evidencia una crítica a la ubicación de los edificios tal y como se habían realizado hasta ese momento.

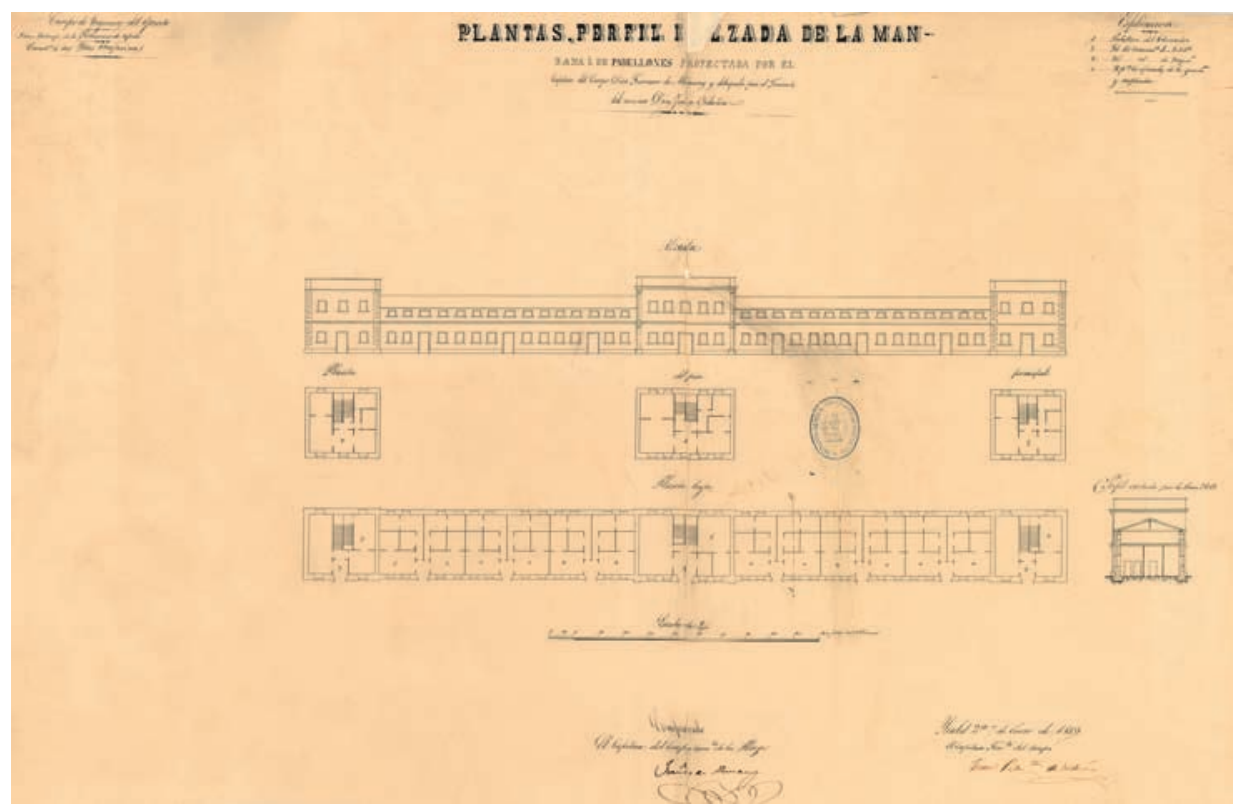

Plantas, Perfil y Alzada de la manzana de pabellones proyectada por el capitán del cuerpo Don Francisco de Alemany. 7 enero 1849. IHCM. ML-03-15.

\section{El proyecto de Juan Manuel de Ibarreta (1849-1850): el fuerte acasamatado y las torres a la martello ${ }^{11}$}

Tampoco se hizo nada de la popuesta anterior de Alemany, e inmediatamente se plantea un nue vo proyecto que tampoco llegó a r ealizarse. Su autor en este caso fue el teniente de ingenieros Juan Manuel de Ibarreta y Ferrer. Se trata de una fortificación de las islas basada en la constricción de un gran fuerte acasamatado en

${ }^{11}$ Plano de Isabel II en que se indican las obras necesarias para su ocupación permanente según el dictamen de la comisión que entiende en este asunto, en esta Dirección General de orden superior. $V^{\circ} B^{\circ}$ Francisco Serrallach, dibujado por el capitán de ingenieros Onofre Rojo. Madrid 23 de febrero de 1849. IHCM Melilla, no 416 y otro igual en 398. 
el centro de Isabel II, armado con setenta piezas de ar tillería y que debía ser vir al mismo tiempo para alojar la guamición y presidio en tiempo de guerra. Este fuerte se complementaba con una batería a barbeta que debía construirse en al noroeste de Isabel II y una torre con capacidad para 30 hombres en los sitios que ocupaban hasta ese momento los blockhaus en las otras dos islas de Congreso y Rey.

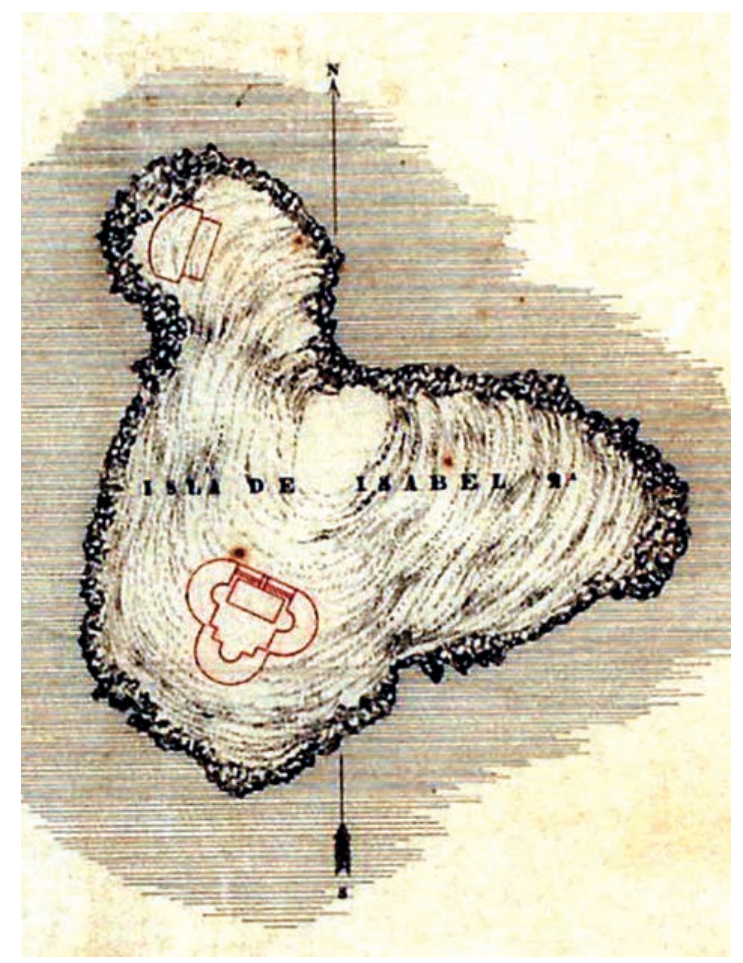

Plano de Isabel II en que se indican las obras necesarias para su ocupación permanente, 23 de febrero de 1849. AIMML. IHCM Melilla, no 416 y otro igual en $n^{\circ} 398$.

Este proyecto fue aprobado por los ser vicios técnicos de Ingenier os de Madrid, y por esa razón dos años después se redacta el proyecto del cuartel que debía construirse en su gola ${ }^{12}$ : un edificio de tres plantas con cubierta a prueba de bomba, de diseño clásico en lo estético y con poitada de prestigio reseñada al estilo barroco.

${ }^{12}$ Plantas y perfiles del edificio situado en la gola del fuerte, Isabel 2ª 23 de febrero de 1851. El teniente comisionado J. Manuel de Ibarreta, IHCM, Melilla nº 400. 
Sin embargo la nueva propuesta tampoco se iba a concretar en nada ${ }^{13}$, por lo que las obras que se acometier on por entonces en las islas se centrar on en consolidar lo ya construido y en todo caso no afectar on al sistema general de fortificación de la isla planteado cuando se realiza su ocupación y que se basaba en las dos baterías al Norte y Sur y una más modesta al Este, y blockhaus en las islas de Rey y Congreso.

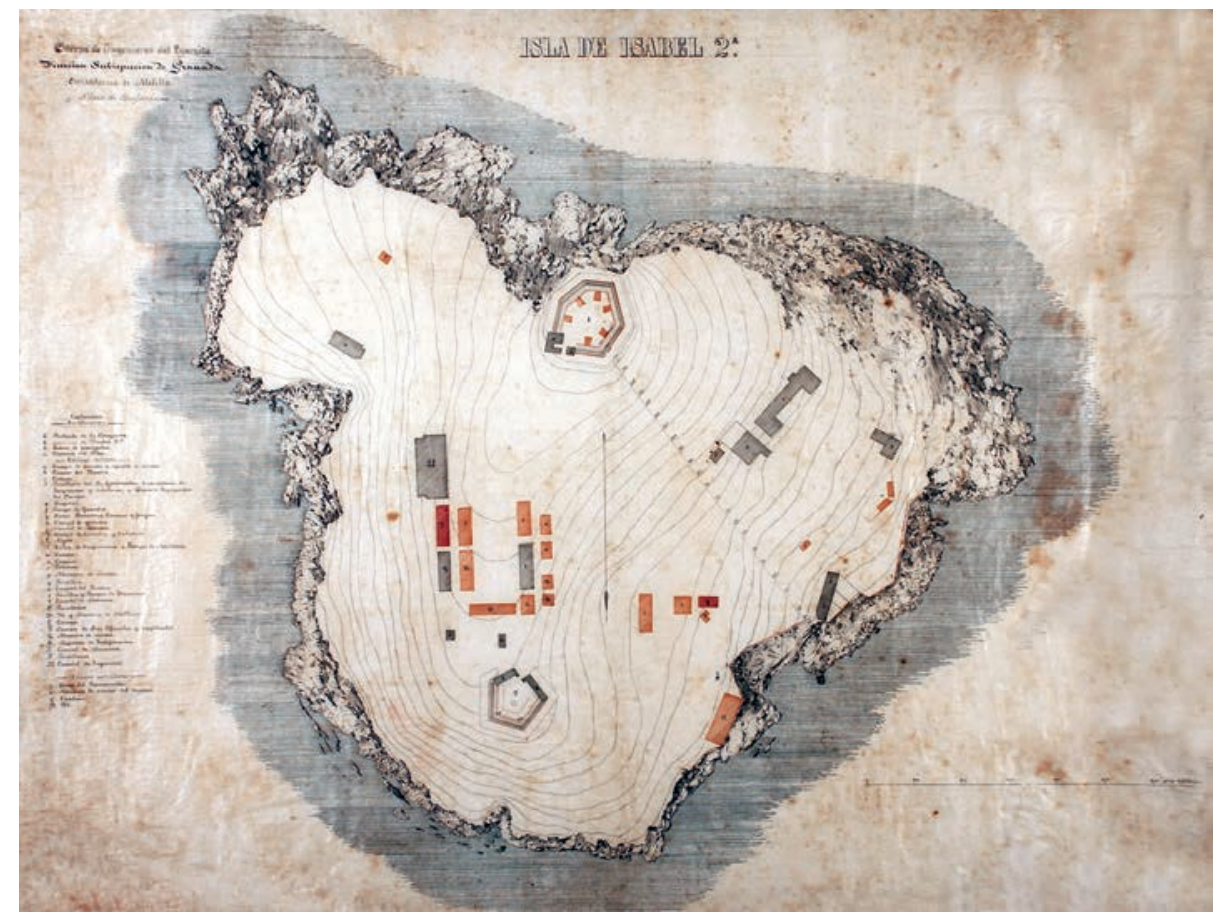

Isla de Isabel 2ª. AIMML, IHCM Melilla n 408. Sin fecha, pero hacia 1850-1856.

Conocemos dos inter esantes planos cor respondientes a este momento cronológico (1850-1856): uno firmado por Ramón de Mascaró ${ }^{14}$ y un segundo anónimo ${ }^{15}$. En ellos ya se percibe un poblado militar con cierta ordenación de manzanas que formaban una plaza cuadrangular en la que toda vía no existía la

${ }^{13}$ La España, de 27-09-1857, señalaba que el pr oyecto había sido realizado por el capitán Juan Manuel de Ibarreta y que su presupuesto se cifraba entre 8 y 10 millones de reales.

${ }^{14}$ Plano de la isla Isabel 2a . Ramón de Mascaró, hacia 1850-1856. IHCM. ML-03-13.

${ }^{15}$ Isla de Isabel $2^{\text {a }}$. IHCM Melilla n ${ }^{\circ} 408$. Sin fecha, pero hacia 1850-1856. 
iglesia y que estaba cerrada al sur por un cuartel proyectado por Alemany. Más al Este se situaba el cuartel del presidio, los almacenes de víveres y el único aljibe que se dice "en construcción” y que se temina en esos años. El hospital se situaba en el Noreste, así como el horno, herrería y la casa del gobernador. Otros edificios completaban el sistema, como el taller de carpintería y parque de artillería situados junto a la muralla.

La muralla ya estaba casi terminada y su planta evidencia los quiebros derivados de la adaptación al terreno irregular donde se asentaba. Por último, señalaremos que también comienzan a v erse varios edificios particulares: la casa del provisionista, el almacén de víveres del mismo y dos cantinas.

En lo que respecta a la fortificación de las islas del Congreso y Rey, Ibarreta diseña entre 1851 y 1852, las propuestas de torres para su defensa.

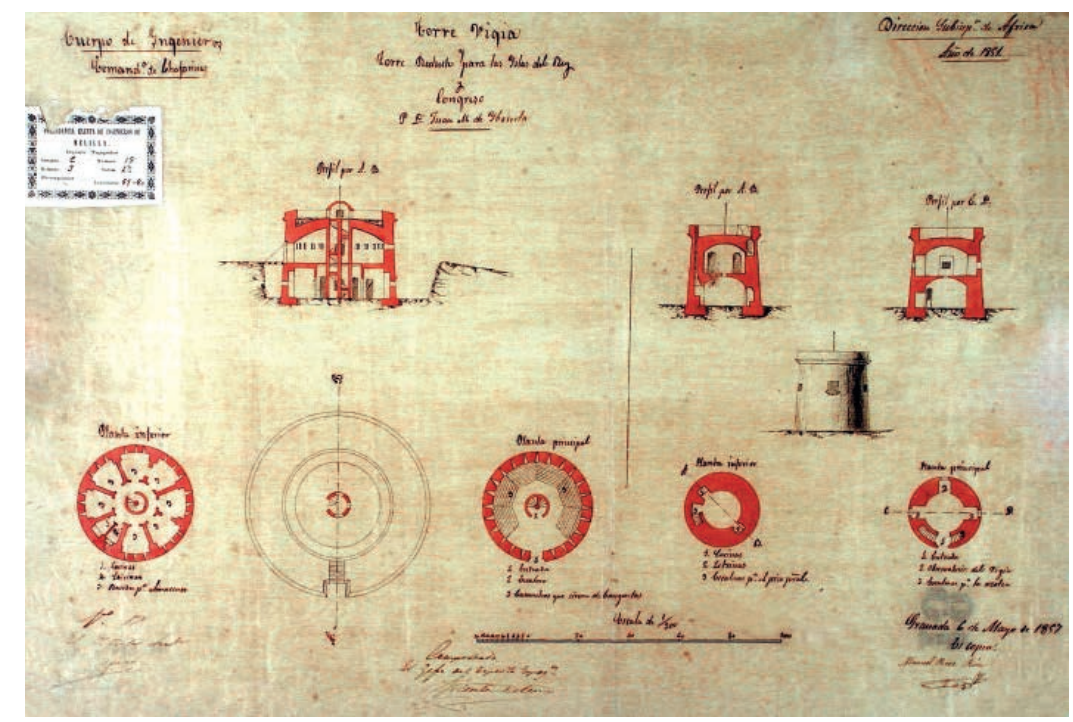

Torre vigía y torre reducto para las islas del Rey y Congreso, P.D. Juan M. de Ibarreta 1851. AIMML. IHCM, Melilla, $n^{\circ}$ 415. Sector del plano anterior.

Entre $1851^{16}$ y $1852{ }^{17}$ conocemos dos modelos diferentes de torres que

${ }^{16}$ Torre vigía y torre reducto para las islas del Rey y Cong reso, P.D. Juan M. de Ibarreta 1851 (aunque es copia de 1857). Granada 6 de mayo de 1857, es copia, Manuel Pérez Ruiz. Comprobado Vicente Beleña, Vº Bo Aparici. IHCM, Melilla, no 415.

${ }^{17}$ Proyecto de unas torres defensivas para las islas Chafarinas. 1 de septiembre de 1852, José Jiménez 
debían ser construidas en las islas del Cong reso y del Rey en sustitución de los blockhaus ${ }^{18}$.

Ambos proyectos, que no llegar on a construirse, se asemejan entre sí al seguir el modelo de tor res denominadas a la martello, que ofrecían capacidad para pequeña artillería y fusil. La grande de dos plantas con foso estaba prevista para la isla del Congreso, y la pequeña, con la misma planta pero sin foso, para la isla del Rey. Este modelo también lo podemos encontrar en algunos de los proyectos que se r ealizaron posteriormente para Melilla y Ceuta. En Melilla por ejemplo fue la tipología que los ingenier os Navarro Ascarza y Francisco Arajol eligen para diseñar una ser ie de pequeñas tor res en sus pr oyectos de $1860 \mathrm{y}$ 1864, y que sería modificado posteriormente por otros técnicos para realizar los proyectos de torres para Camellos, Cabrerizas Bajas y San Lorenzo.

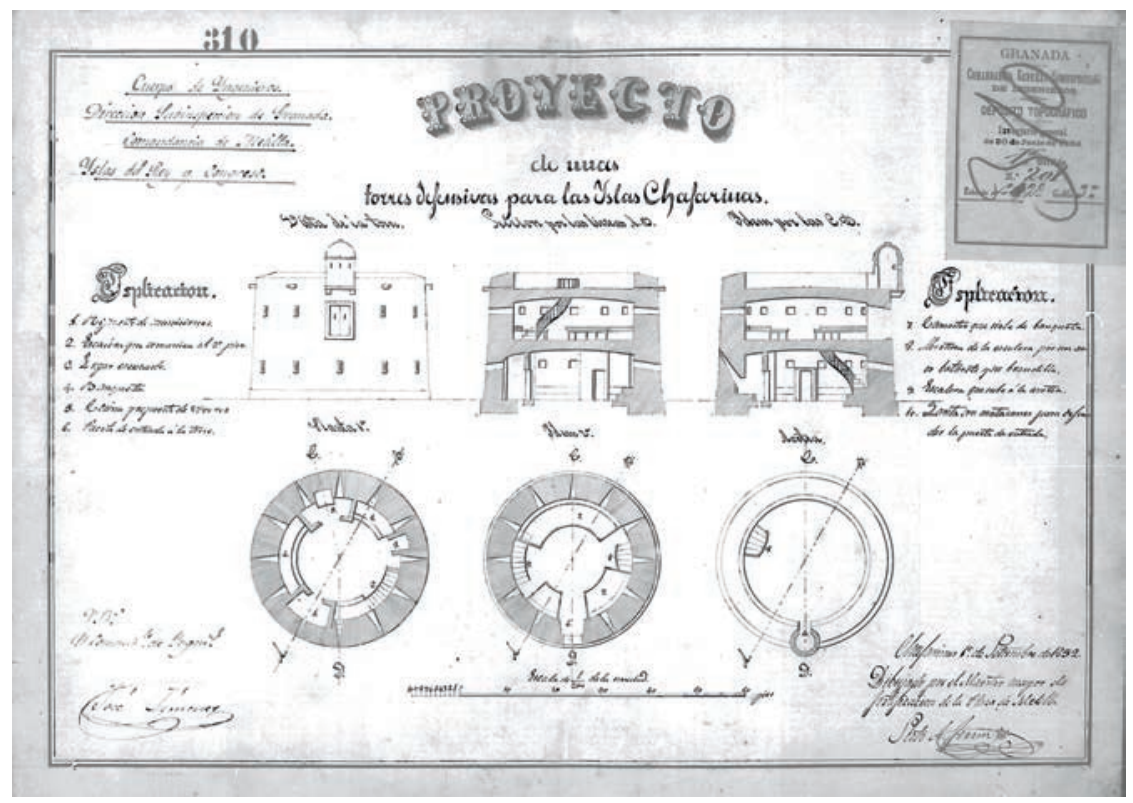

Proyecto de unas torres defensivas para las islas Chafarinas. 1 de septiembre de 1852. AGMM, R821/1.

dibujado por el maestro mayor de fortificación de la ciudad de Melilla Sixto A. Ferrín. Forma parte del expediente Memoria sobre la fortificación permanente que se ha de ejecutar en las islas Chafirinas según dictamen de la Dirección General del Arma, 31 de marzo de 1851. Juan Manuel Ibarreta. AGMM, R821/1.

${ }^{18}$ El dibujo de los blockhaus puede verse en el Plano del fondeadero de las islas Chafirinas en dos vistas levantado por el ... de navío D Jose Espin. CGE 017. 


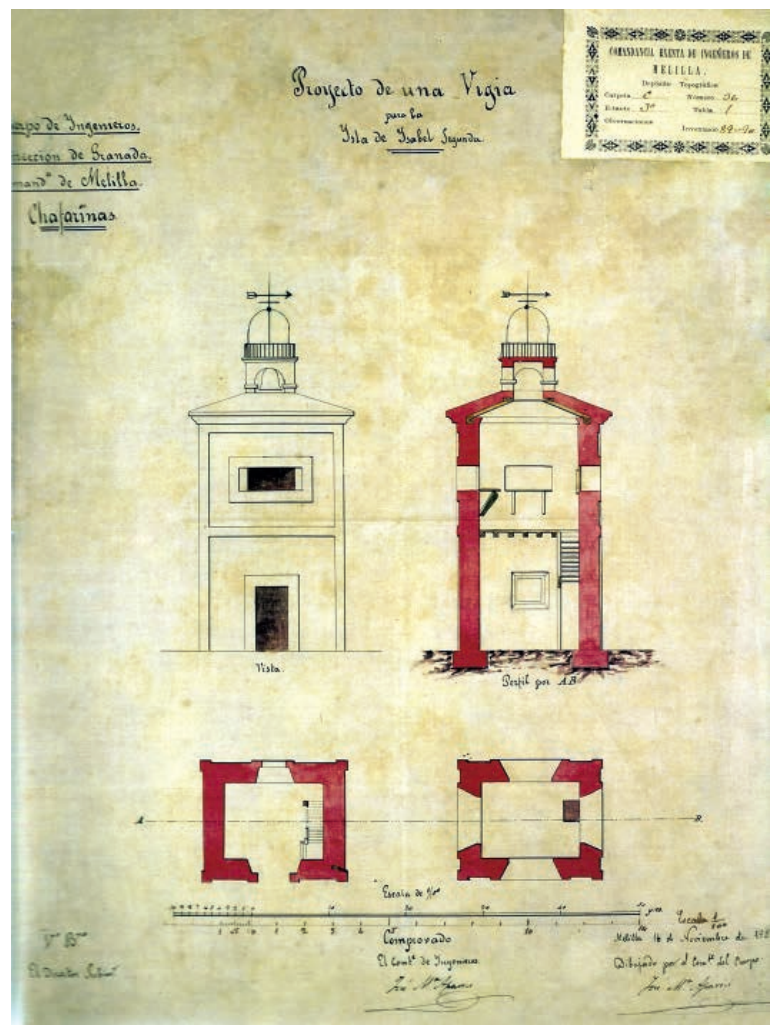

Proyecto de unaVigía para laYsla de Isabel Segunda. Melilla 16 de noviembre de 1856. AIMML IHCM, Melilla, $n^{\circ}$

\section{Las obras hasta 1857}

Sin embargo, no parece que las circunstancias fueran propicias para llevar a cabo la transformación defensiva de las islas que los técnicos aconsejaban. En varias memorias de obras entre 1851 y 1855 , se refleja claramente la poca importancia de los trabajos y las penosas limitaciones y carencias en todo orden de cosas: los problemas derivados de los ma teriales (extracción de piedra, construcción de adobes) y su transpor te (la cal procedía de Málaga al igual que la piedra de buena calidad para las barbetas). Los materiales que se encontraban en las islas no eran buenos: la arena era de mala calidad y se utilizaba corientemente agua salobre en las obras, lo que reportaba serios problemas en las construcciones. Finalmente, para terminar de complicar la situación, la mano de obra era poco cualificada. 
El problema de la poca cualificación de los operar ios determinaba que ciertas obras no pudieran teminarse, caso de dos aljibes que estaban g excavados en la roca pero en los que no se podía acabar su revestimiento interior, cosa que ocurre en 1853 y 1854.

Por su parte, 1855 es un año impor tante en esta secuencia cr onológica. Era evidente que debía tomar se por el Gobierno de España una decisión sobre las islas; o bien asumir su refuerzo en todos los órdenes, o bien su abandono. El 7 de mayo de 1855 se for maba una comisión pr esidida por el gober nador de Melila, Manuel Buceta y compuesta entre otros oficiales por el comandante de ingenieros Ángel Romero y el capitán de ar tillería Manuel Castro, que debían informar sobre Chafarinas y sobre la necesidad de construir un puerto. El informe se terminó en julio y calculaba unas obras cifradas en $250.000 \mathrm{r}$ eales, empleando confinados para los trabajos,con la construcción de la escollera de unión entre Isabel y Rey ${ }^{19}$.

Estos datos nos indican que todos los pr oyectos y propuestas que hemos estudiado sobre las Chafarinas estaban descartados, tanto el fuerte grande en Isabel II, como las torres en las otras islas. Para terminar de arreglar las cosas en 1856 la Junta de Defensa Permanente del Reino propuso abandonar las Islas Chafarinas.

Ese mismo año las islas cuentan con un ingenier o de fuer te capacidad y prestigio: José María de Aparici y Biedma ${ }^{20}$. Será este ingeniero quien nos aporte las noticias de las obras, construcciones y proyectos durante estos años. Por él sabemos que se continuaban las obras de la biería del Piles y que los Blokhaus en

${ }^{19}$ MORALES MENDIGUTÍA, Gabriel de (1909). Datos para la Historia de Melilla; p. 203.

${ }^{20}$ APARICIY BIEDMA, José. Nació enValencia el 22 de febrero de 1824. Ingresó en la Academia de Guadalajara en 1838 procedente del Regimiento de Infantería «Almansa» donde servía como cadete. Sale de la Academia en 1842, destinado al primer Regimiento de Zapadores, con el que toma par te en 1843 en el sitio de Sevilla donde construye dos baterías y un puente, poniendo en estado de defensa el convento de San Benito. En 1845 marcha a París comisionado para el estudio de un gimnasio y parque de incendios, lo que materializaría a su vuelta, en el Regimiento de Zapadores, en Guadalajara. Escribe y publica un manual de Zapadores-bomberos, otro de Gimnasia (en ambos casos los primeros de sus respectivas especialidades publicados en España), y unas «Lecciones elementales de fortificación». En 1859 toma parte en el Ejército expedicionario de África, destacando en numerosas acciones como las batallas de castillejos, Tetuán y Wad-Rass. En 1874 era brigadier de Ingenieros, destinado en la Dirección General del Cuerpo, pero conservando la dirección de las obras del palacio de Buena vista. En 1886 asciende a Mariscal de Campo, siendo destinado como jefe de la Dir ección- Subinspección de Castilla la Nue va. Publicó numerosos trabajos en la revista Científico-Militar. Murió en 1894. 
Rey y Congreso se mantenían en pie a duras penas. También nos da cuenta de la continuación de las obras de los aljibes, dándose por ter minada la excavación total del llamado de la Marina en mayo 1856 y el de la Bajada al Muelle a finales del mismo año ${ }^{21}$.

Lo que sí realiza Aparici en este momento es el proyecto y la construcción de una torre vigía de planta cuadrangular de dos plantas ${ }^{22}$ con campana y que posteriormente haría la función de faro hasta la construcción del faro actual.

\section{Las obras y el proyecto de José María Aparici de 1857}

José María Aparici redacta un interesante informe ${ }^{23}$ con fecha 28 de febrero de 1857 totalmente contrario al abandono de las islas. Reiteraba sus críticas a las fortificaciones realizadas hasta el momento: tres baterías a barbeta y dos blockhaus ruinosos, así como la inexistencia de puer to, puesto que la idea central de Aparici es que "el puerto de Melilla está en Chaf arinas". También era crítico con el sistema seguido en la ejecución de las obras, señalando en el informe el problema del agua: "los gastos de agua desde la ocupación han supuesto medio millón de reales”.

Como consecuencia de este informe, el Ingeniero General ordena aAparici el 7 de agosto de 1857 iniciar un nuevo proyecto de defensa de las islas ${ }^{24}$ y éste realiza una memoria de obras que firma el 23 de septiembre del mismo año ${ }^{25}$.

Una de las primeras preocupaciones de Aparici fue computar la mano de obra necesaria para su proyecto (que cifraba en ciento veinte operarios y cuatrocientos confinados), así como la previsión de su alojamiento y los servicios necesarios para su estancia en las islas. Por esa razón plantea un nue vo cuartel de

\footnotetext{
${ }^{21}$ Memoria de obras, 1856.- Aparici 651/7.

${ }^{22}$ Proyecto de una Vigía para laYsla de Isabel Segunda. Melilla 16 de noviembre de 1856, dibujado por el comandante del cuerpo José María Aparici. IHCM, Melilla, $n^{o}$

${ }^{23}$ Memoria, $1261 / 1$.

${ }^{24}$ Plano de la Ysla de Isabel $2^{a}$, que acompaña al pr esupuesto formado por el comandante D. José María Aparici de las obras que ha proyectado con arreglo a las instr ucciones del Exmo. Señor Ingeniero General del 7 de agosto de 1857. ML-03-18. Granada 25 de septiembre de 1857, dibujado por el comandante José María Aparici. $V^{\circ} B^{\circ}$ el coronel director subinspector into. Manuel Valdés. Hay otros dos muy similares de 16 de octubre. Dibujados por Ricardo Valdivieso, IHCM, Melilla, no 405, y ML-03-17

${ }^{25}$ La memoria las firma Aparici el 23 de septiembre de 1857. 651/8.
} 
confinados, aunque también pr eveía que, cuando las obras se concluy eran, el edificio podría servir para ubicar los talleres y maestranza de ingenieros.

Otro de los problemas fundamentales era la previsión del agua necesaria para las obras. El único sistema viable era traer agua en barcos a un alto coste, o bien hacer aljibes nuevos que permitieran utilizar el agua de lluvia, descartando el uso del agua salobre. De los aljibes, señala Aparici que existía uno de 11.000 arrobas (llamado de la Provisión) y dos en construcción (uno llamado de la Marina y otro de la Bajada al Muelle) de los que faltaba solamente revestir las paredes y hacer las bóvedas y que aportarían otras 50.000 arrobas más de agua que consideraba suficientes. Primero debería hacerse el llamado de la Marina, recogiéndose en el otro las "aguas llovedizas para las mezclas".

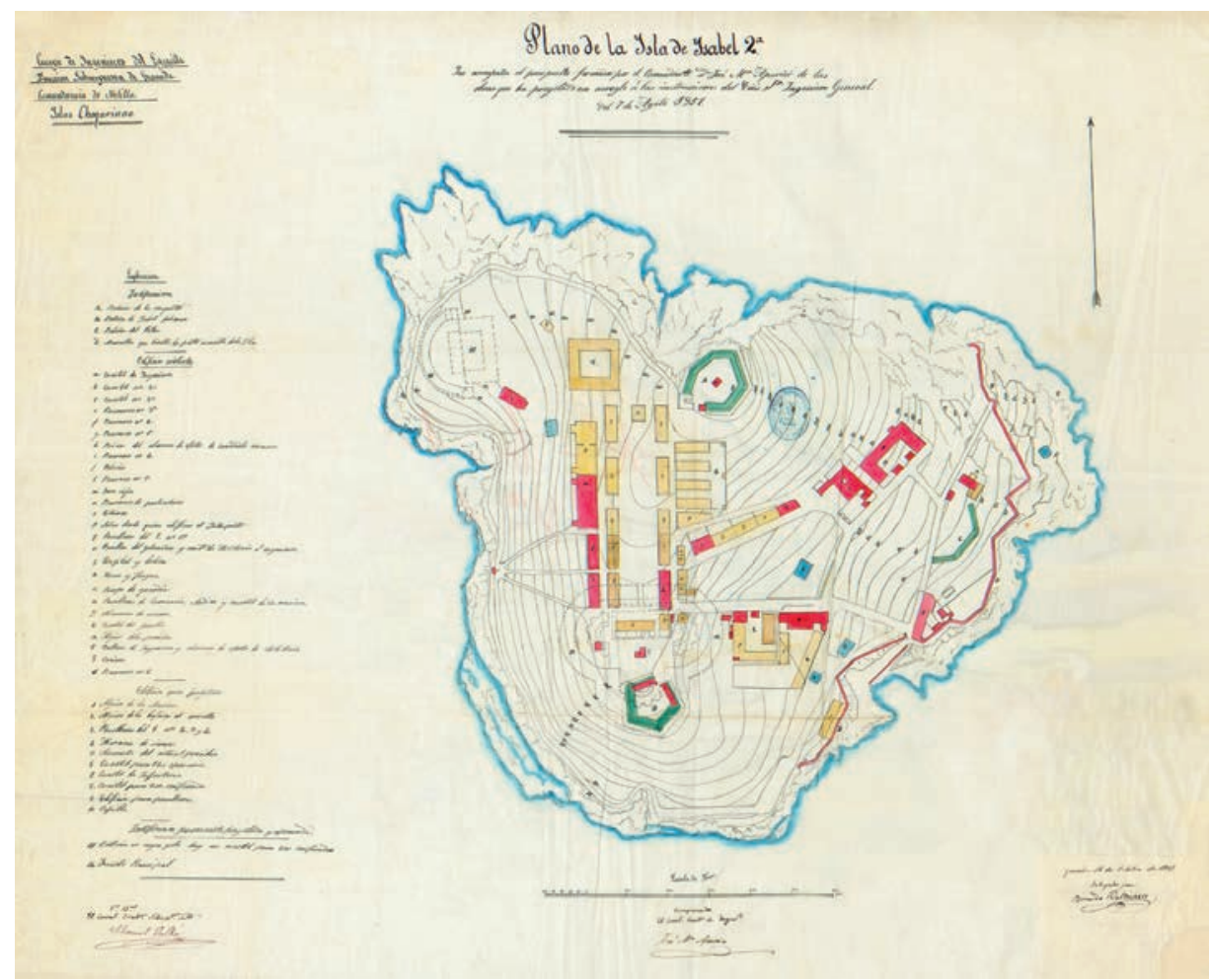

Plano de laYsla de Isabel 2a , José María Aparici. IHCM. ML-03-18. 25 de septiembre de 1857

Las fortificaciones de la isla de Isabel II se ciñen por entonces a lo que se proyectó desde el inicio: las dos baterías de la Conquista y la de Isabel I (ambas 
dotadas con un obús de a 9 larga cinco cañones de a 24 y un moitero), la batería del Piles y la muralla de la zona este/sureste de la isla ${ }^{26}$.

Lo proyectado por José María Aparici en 1857 se centra fundamentalmente en terminar de definir las necesidades de las islas, en cuanto a los edificios necesarios para su defensa. No r epresenta por tanto una pr opuesta nueva en cuanto a su fortificación, sino un fortalecimiento y racionalización de lo que ya existía, mejorando lo proyectado anteriormente.

Aparici consolida la trama urbana de la isla de Isabel II, determinando su centro en la plaza rectangular que debía presidir una iglesia. Para ello proyecta varios pabellones que delimitan al Este la citada plaza, determinando la idea de una población con cier ta ordenación urbana y que $r$ equería varios desmontes previos. También proyecta la construcción de varios cuarteles, como el destinado para 200 presidiarios de forma cuadrangular con patio central, que posteriormente se llamó cuartel de operarios.

Determina asimismo la ordenación de una calle de subida a la zona alta, con algunas construcciones y la zona de lo que sería presidio, cerrando en cierto modo la estructura urbana de la isla prácticamente como se mantuvo durante el resto del siglo XIX y buena parte del XX.

El tema del puerto es una parte importante del plan de defensa deAparici ya que estaba convencido de que sin realizar un nuevo puerto el sistema defensivo no serviría para nada. Por esa razón realiza varias propuestas que ya han sido analizadas en el capítulo cor respondiente a la historia del puer to por parte de Francisco Narváez. En cuanto al faro, Aparici nos señala que había un mal farol en la batería de la Conquista, pero que una nue va luz sería le vantada sobre la torre que se estaba construyendo en el centro de esa batería, con una altura de 180 pies (unos 55 metros), que podría ser vista a 18 millas Complementado esta farola, sobre la parte más alta de Congreso también había prevista una torre vigía y en ella podría poner se otra luz, aunque Aparici prefería las obras en Isabel II por ser más fáciles de controlar.

\footnotetext{
${ }^{26}$ Signatura 651/8. Granada 23 de septiembre de 1857, José María Aparici.
} 


\section{El proyecto de Aparici-Lombera de $1859^{27}$}

En 1859 se va a redactar el proyecto más ambicioso que jamás se hubiera planteado sobre las islas Chafarinas ${ }^{28}$. Sus autores fueron, Juan Manuel Lombera y José María Aparici. De haberse llevado a cabo hubiera per mitido contar hoy con uno de los conjuntos for tificados más interesantes del siglo XIX español, basado en el sistema de fortificación poligonal con casamatas flanqueantes.

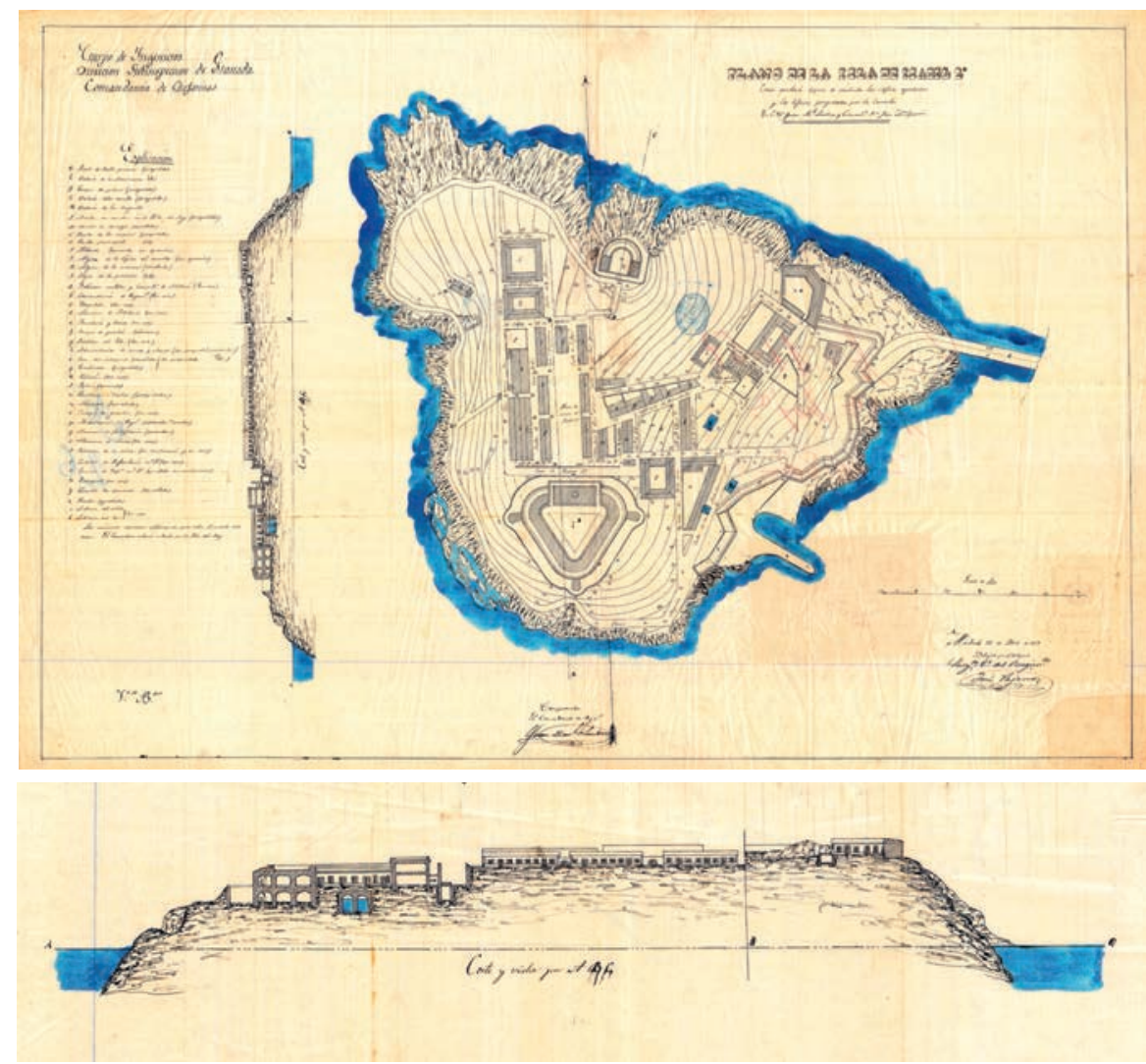

Plano y perfil Norte-Sur del plano de la isla de Isabel $2^{a}$ como quedará después de concluidos los edificios aprobados y las defensas proyectadas por los coroneles T.C. Don Juan Manuel Lombera y Comandante Don José María Aparici. Madrid, 16 de abril de 1859. IHCM. ML-03-10.

${ }^{27}$ Proyecto de fortificación, edificios y puerto de las islas Chafarinas, 10 de enero de 1859, Lobera y Aparici, AGMM, sig. 4-5-9-12. 74 folios. Contiene varios planos.

${ }^{28}$ Plano de la isla de Isabel $2^{a}$ como quedará después de concluidos los edificios aprobados y las defisas proyectadas por los coroneles T.C. Don Juan Manuel Lombera y Comandante Don José María Aparici. Madrid, 16 de abril de 1859. Dibujado por el dibujante sargento $2^{\circ}$ del Regimiento José Pajarero. Comprobado Juan Manuel Lombera. ML-03-10. 
Aunque no llegó a r ealizarse, el proyecto nos sirve para entender cómo la fortificación había evolucionado radicalmente en pocos años, y es que, en palabras de los autores: "Chafarinas no es ni debe ser otra cosa que una plaza militar" ${ }^{2}$.

El objetivo principal de este proyecto consistía en defender las islas de un supuesto ataque llevado a cabo por una flota enemiga, realizado desde la bahía, razonando que desde alta mar se consideraba que el ataque sería imposible. Por esta razón había que b uscar tres puntos defensivos en las tr es islas: cualquier barco que entrase en la bahía formada por las Chafarinas estaría batido de una u otra forma desde uno de los puntos. La importancia de los fuer tes de las islas menores es fundamental en este proyecto, potenciando el flanqueo entre ellos.

a) La isla de Isabel II contaría para su defensa con arios fuertes. Al Norte se situaba la ba tería de la Conquista en for ma de media luna con cua tro piezas cubiertas con casamatas destinada a vigilar el mar exterior, en todo su flanco norte.

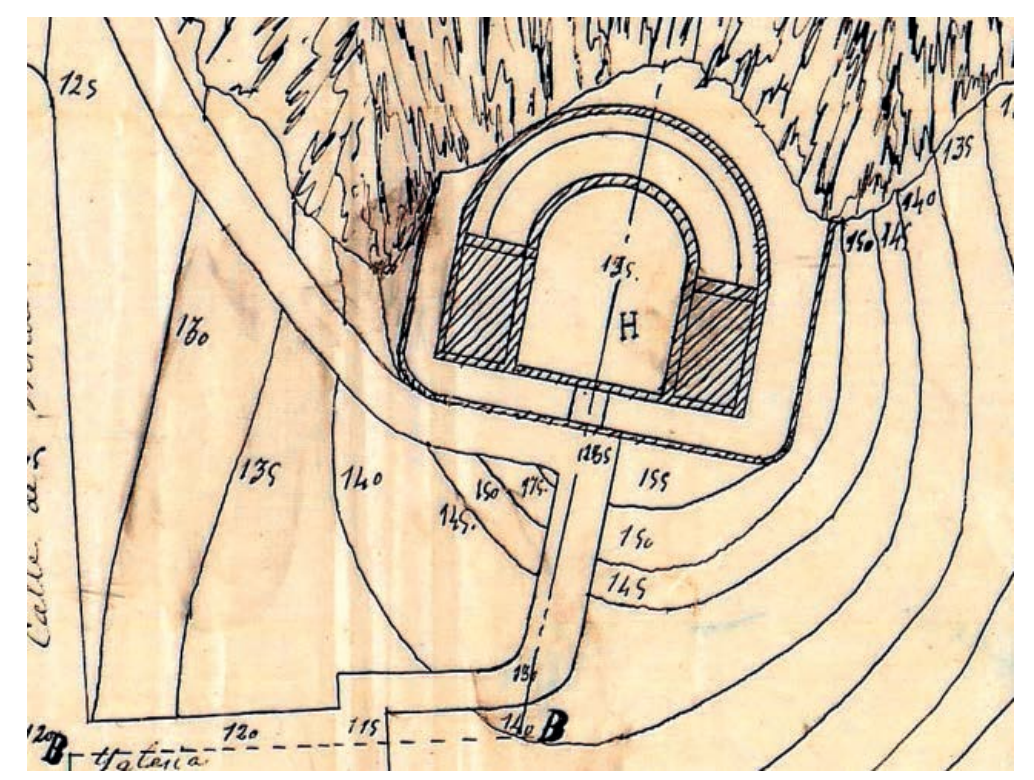

Batería de la Conquista en el Plano de la isla de Isabel $2^{a}$ por los coroneles T. C. Don Juan Manuel Lombera y Comandante Don José María Aparici. Madrid, 16 de abril de 1859. ML-03-10.

${ }^{29}$ Memoria descriptiva que acompaña al proyecto y presupuesto de las obras que para la defensa de las islas consideran indispensables los coroneles Juan Manuel Lombera y José María Aparici, 1859, Madrid 8 de abril de 1859. Rf. $651 / 12$. 
Al Sur se situaba el fuerte de Isabel II ${ }^{30}$ que se concebía como la obra pincipal de la isla y r educto de seguridad en su caso para toda la pob lación, capaz de albergar a mil hombres y que debía contar con cincuenta piezas de artillería.

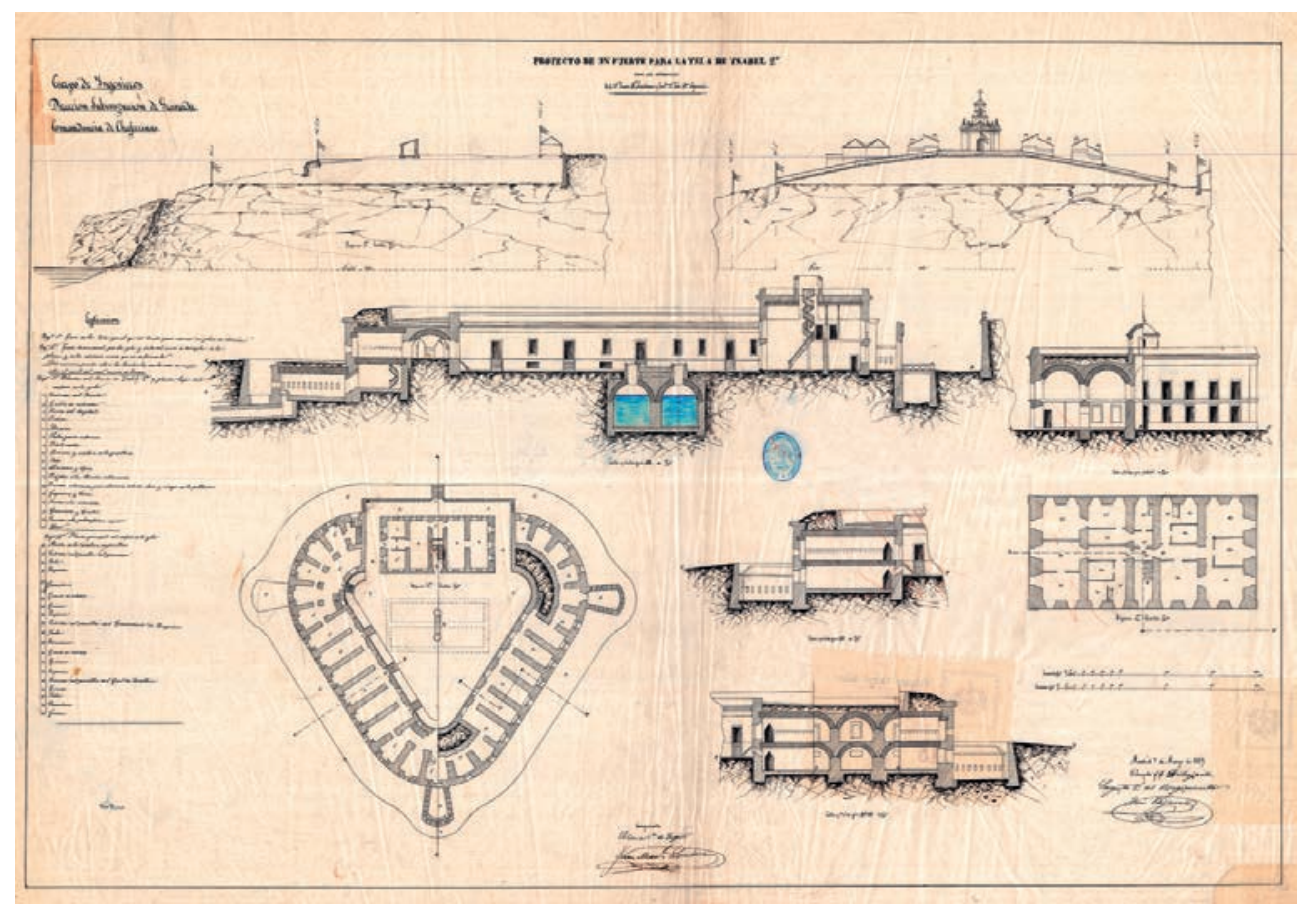

Proyecto de fuerte para la Ysla deYsabel II 7 de marzo de 1859. IHCM. ML-03-09

Se trata de un fuer te en forma triangular de vértices redondeados y con caponeras flanqueantes fusileras en el foso . Contaba en su inter ior con veintinueve casamatas en sus caras y dominaba toda la bahía. En su interior se proyectaba un aljibe para 99.000 arrobas de agua y destacaremos un interesante edificio noble a construirse en la gola del fuer te, sede de las pr incipales autoridades y guarnición de la isla.

${ }^{30}$ Proyecto de fuerte para laYsla deYsabel II por los coroneles T.C. Don Juan Manuel Lombera y Comte. Don José María Aparici. Madrid, 7 de marzo de 1859, dibujado por el dibujante Sargento $2^{\circ}$ del Regimiento José Pajarero. Comprobado Juan Manuel Lombera. ML-03-09. 


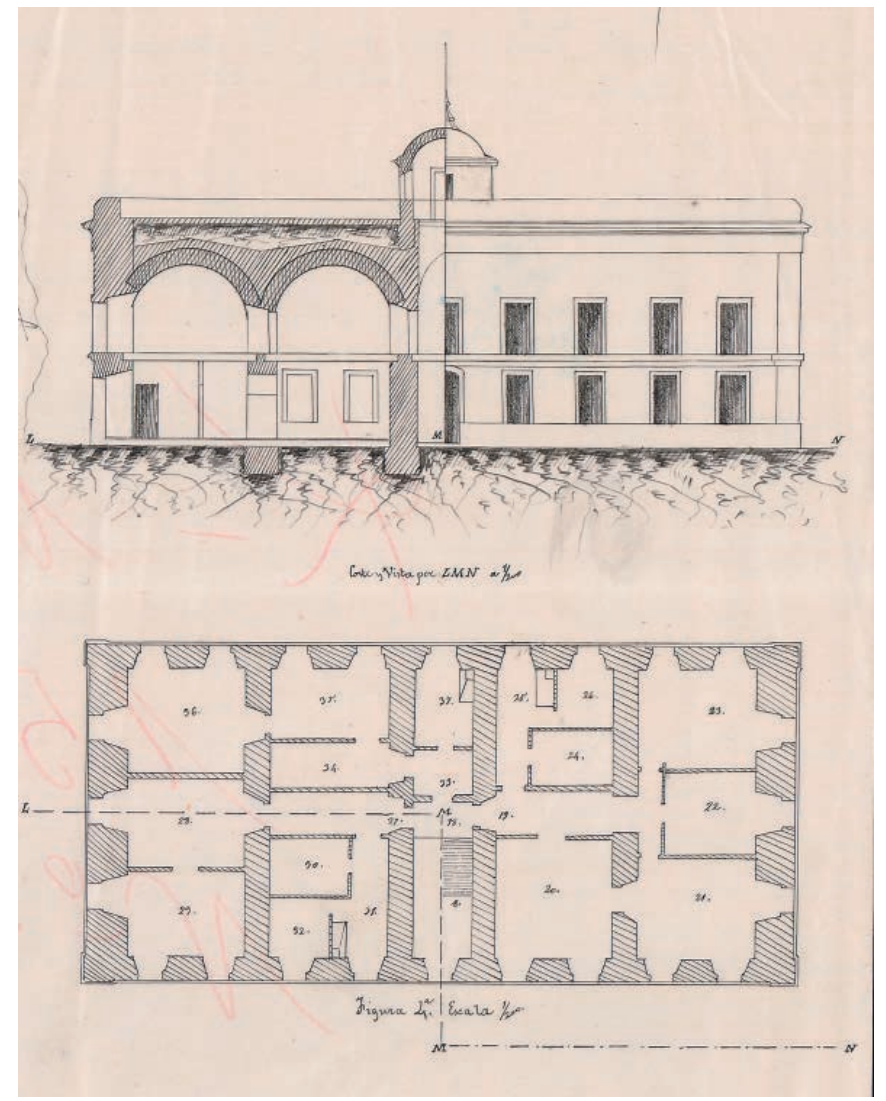

Edificio en la gola, detalle del Proyecto de fuerte para laYsla deYsabel II 7 de marzo de 1859. ML-03-09

Las murallas proyectadas se basan en las ya existentes, adaptadas a la irregularidad del acantilado, contaban con glacis y parapetos de siete pies de anho (unos dos metros). Las murallas comienzan en un fuerte o batería de ocho piezas, llamada batería del Muelle que se proyectaba junto al hospital y que debía vigilar el norte de la isla y la unión con Re y. Esta batería de planta pentagonal contaba con oc ho casamatas abiertas por la gola, con sus respectivas piezas artilleras.

La muralla se continuaba luego con quiebıos hasta situarse encima del puerto, donde se proyectaba una batería abierta, llamada de la Maestranza. Esta contaba también con ocho piezas y su forma era poligonal con tres líneas que determinan ángulos muy obtusos. En el proyecto figura como“"ya realizada” y se corresponde con la posterior batería de losTristes que se realiza años más tarde. En el proyecto se le adscribían nueve casamatas abiertas en la gola. 


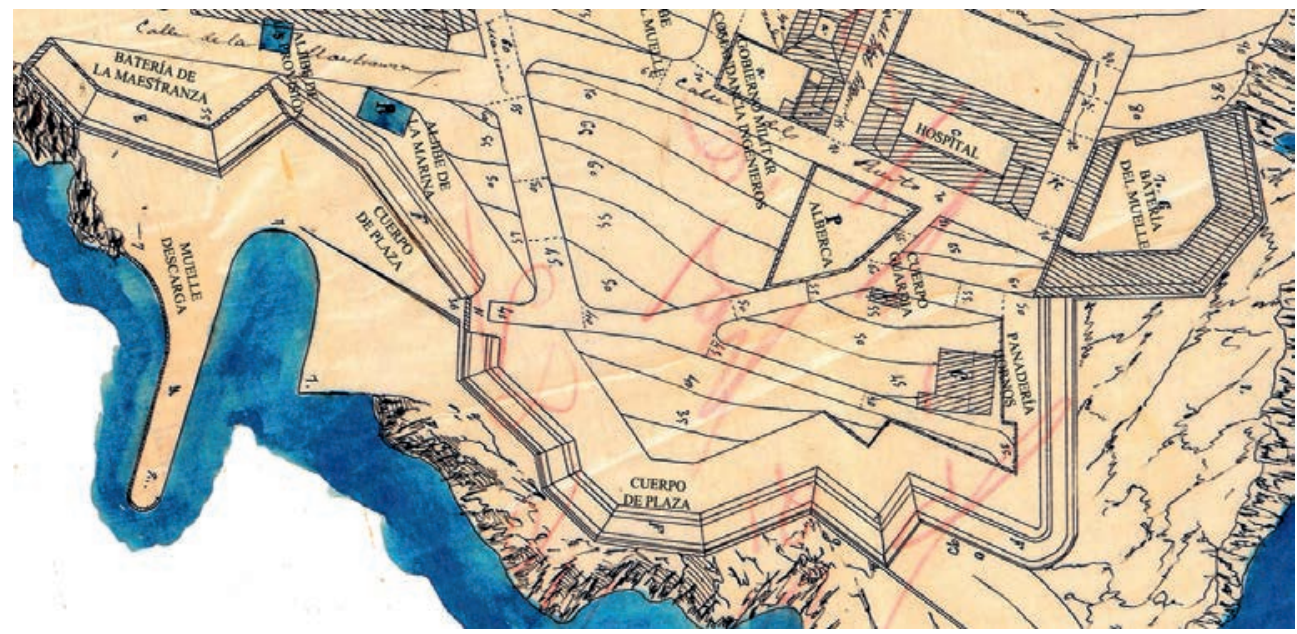

Sector de las murallas en el Plano de la isla de Isabel $2^{a}$ por los coroneles T.C. Don Juan Manuel Lombera y Comandante Don José María Aparici. Madrid, 16 de abril de 1859. ML-03-10.

b) Isla del Congreso.

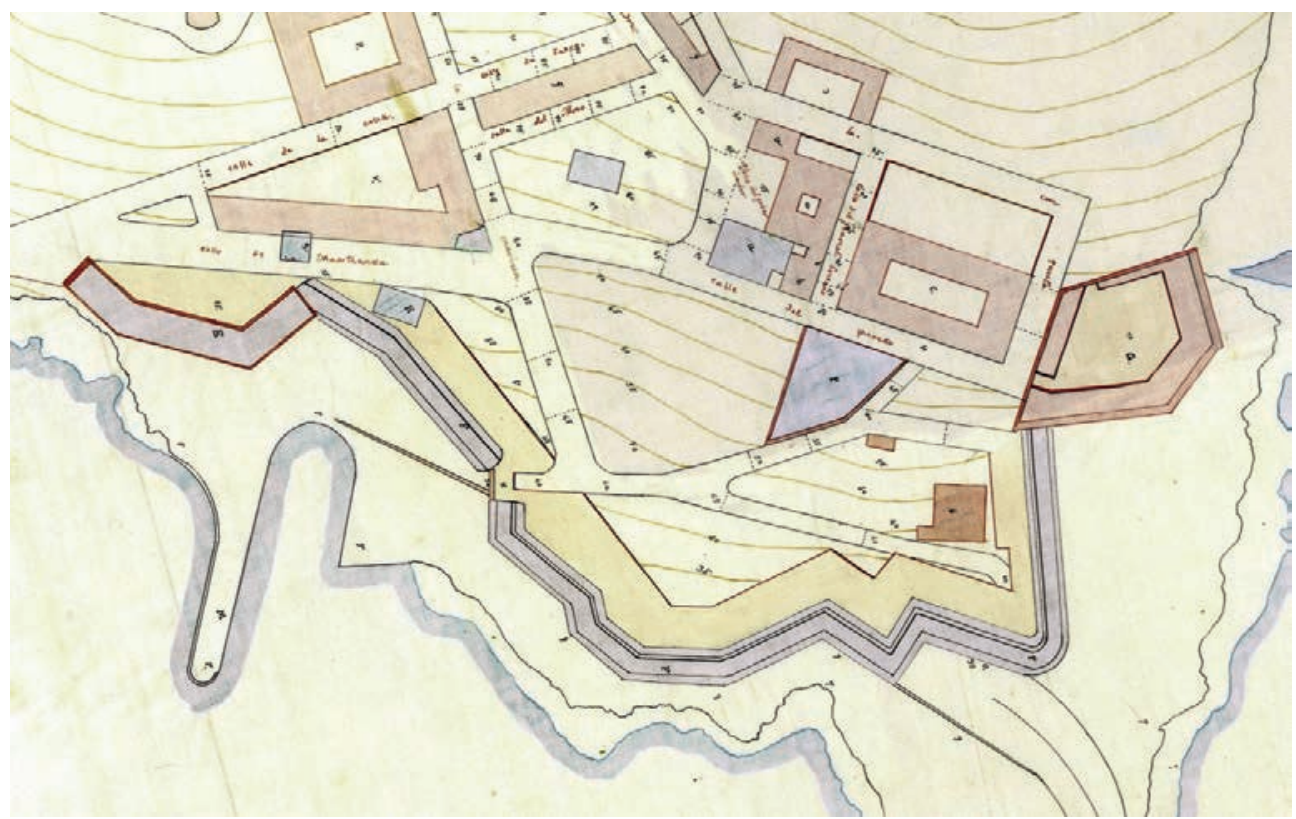

Proyecto de un fuerte para la isla de Congreso. 1859. José Manuel Lombera y José María Aparici. AGMM, 4-5-9-12. 
En Congreso se planteaba un fuerte ${ }^{31}$ autosuficiente, armado de lombardas con veinticinco piezas y cien hombres de guarnición (setenta y nueve artilleros y veinticinco infantes). Su planta es triangular, rodeado de foso, con los ángulos muy redondeados y las caras estaban dirigidas hacia el Sur, la costa, la isla de Isabel y el Norte. En la gola se situaba,cerrándola, un edificio a prueba de bomba con cuerpo de guardia, almacén de artillería, polvorín, almacén de víveres y letrinas. La parte principal del fuerte son quince casamatas abovedadas que sirven también de alojamiento para soldados y en las uniones $r$ edondeadas entre la gola y las caras del fuerte se situaban dos barbetas, una para cuatro piezas y otra para seis En el centro del patio se diseñaba un aljibe con capacidad para 38.400 arrobas.

c) Isla del Rey.

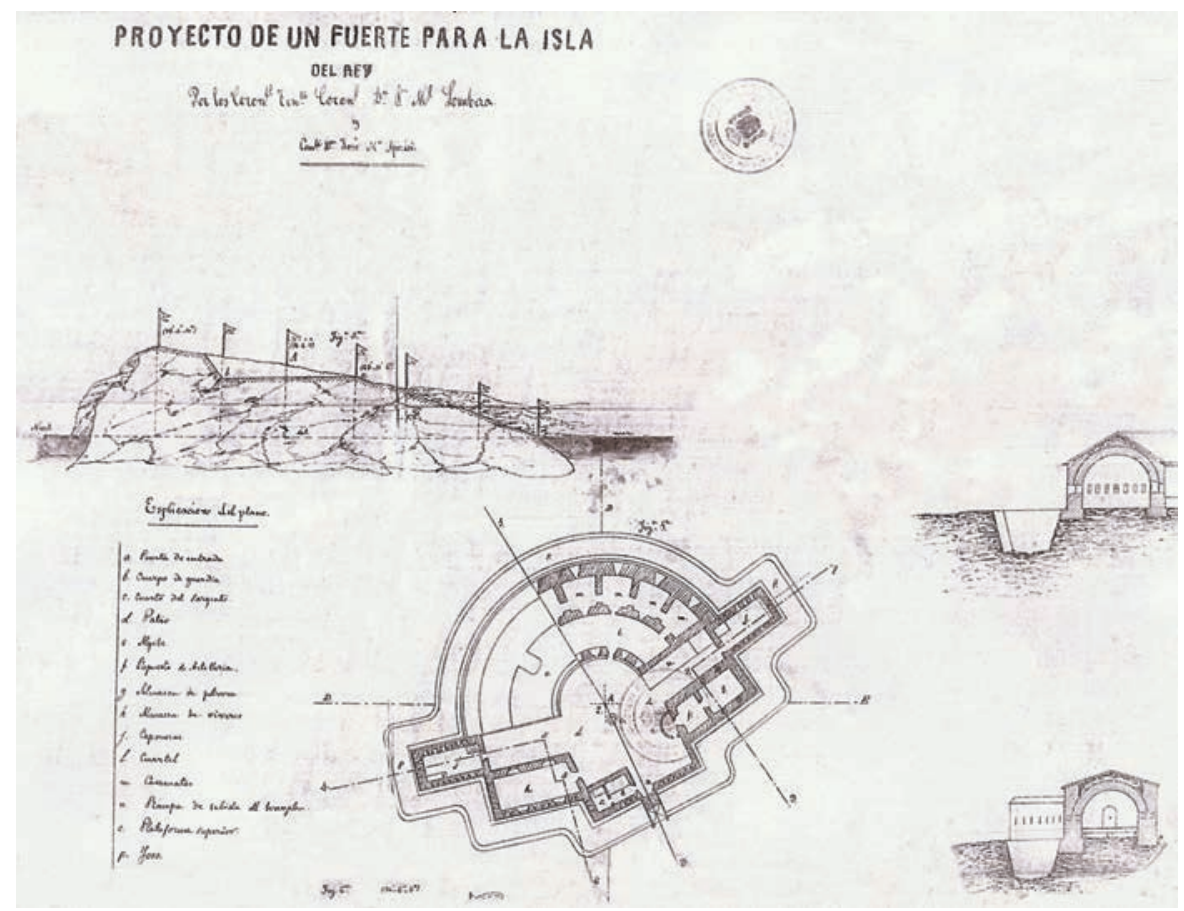

Proyecto de un fuerte para la isla del Rey, 1859. AGMM. 4-5-9-12.

${ }^{31}$ Proyecto de un fuer te para la isla de Cong reso. 1859. José Manuel Lombera y J osé María Aparici. AGMM, 4-5-9-12. 
Por su parte, en la isla del Rey se proyectaba otro fuerte, construido en "el segundo diente" de la isla ${ }^{32}$ capaz para albergar a cien hombr es. Su misión era flanquear la bahía con las demás defensas de las otras islas. La figura de la parte principal de este fuerte es semicircular y tenía doce casama tas para sendas piezas, los fosos flanqueados por dos caponeras para fusilería y en el cento un aljibe capaz de almacenar 21.000 arrobas de agua.

La isla se complementaba con otras dos bđerías, una de seis piezas al Norte denominada O'Donnell, y otra al Sur de cuatro piezas llamada Serrano. Ambas de planta circular con casamatas abiertas por la gola y aljibe.

No podemos obviar que este proyecto surge en un momento histórico de gran trascendencia en el ámbito nor teafricano. En 1859 se produce el acuerdo de los límites de Melilla, en 1860 se desar rolla la guerra de Tetuán (en la que Aparici participa personalmente) y en 1863, se acuerda que Chaf arinas fuese puerto franco, para potenciar su capacidad comercial.

\section{El problema del agua y los aljibes}

El tema del agua es un problema permanente en Chafarinas, y a la lógica necesidad del agua potable para consumo de la población, se ha sumado siempre la del agua no salobr e para ejecutar las obras . Como ya vimos el primer aljibe comienza a excavarse en los primeros días de la ocupación, pero a pesar del alto gasto que suponía traer el agua en barcos cistemas, en 1857 existía sólo un aljibe terminado (el de la Provisión) y sólo dos años después se había conseguido terminar otro (el de la Mar ina), estando en ejecución un tercer o llamado de la Bajada al Muelle. Los tres se situaban m uy cercanos entre sí, debido a que la escorrentía del agua de lluvia terminaba yendo a dos puntos concretos de la isla, y se elegían estos puntos para $r$ ecoger la mayor cantidad posible de litros. En otros momentos también se ejecutaron balsas o albercas para recoger agua, con una finalidad más perentoria y destinada a las obras.

Por otra parte, en todos los pr oyectos de fuer tes que hemos analizado, figura siempre la existencia de un aljibe en su inter ior. Este nuevo modelo de aljibe situado en el centro del patio de una construcción también va a ser aplica-

\footnotetext{
${ }^{32}$ Proyecto de un fuerte para la isla del Rey, 1859. AGMM. 4-5-9-12.
} 
do finalmente en algunos de los edificios que se construirán en las islas hasta los primeros decenios del siglo XX.

En 1868, conocemos una serie de planos de gran interés que nos muestran las características de cuatro de los aljibes existentes, su tipología y capacidad, lo que nos permite entender mucho mejor su funcionamiento. Son los siguientes:

Aljibe de la provisión ${ }^{33}$, es el más antiguo y contiguo al almacén de víveres, servía de depósito al agua procedente de Málaga. Disponía de un conducto que comunicaba con el puer to y donde el buque vapor vertía el agua potable. Este conducto pasaba por un pequeño recipiente y de allí al depósito. Su cubierta era abovedada en cuya clave se abría la garita que custodiaba el depósito.

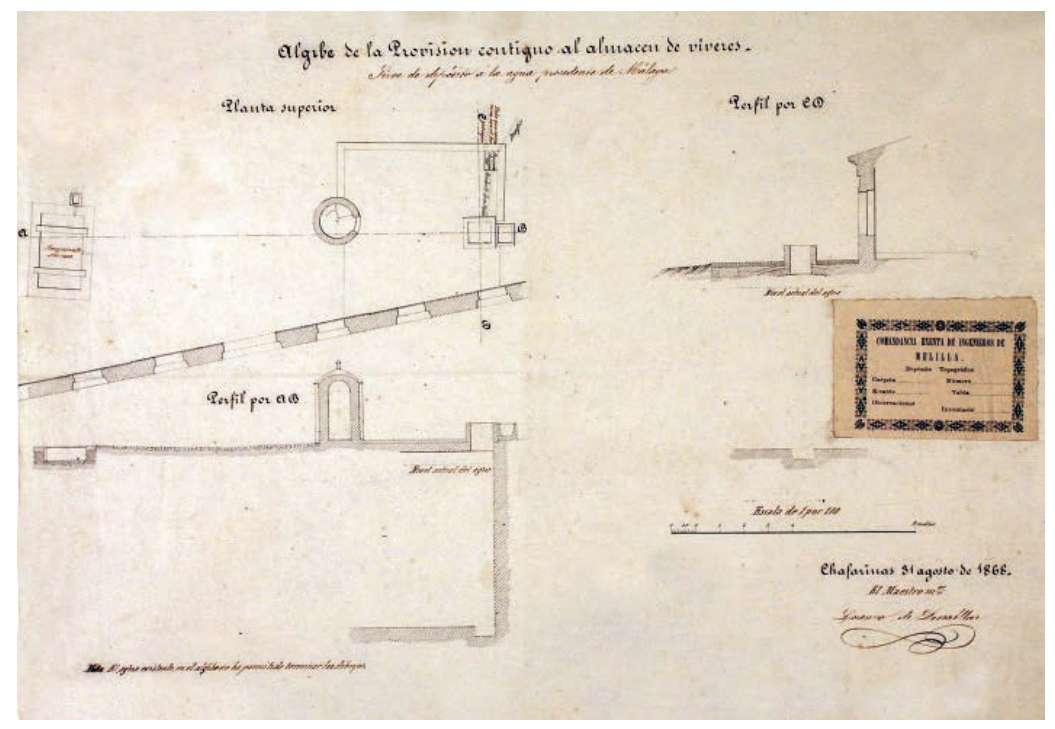

Aljibe de la provisión contiguo al almacén de víveres. AIMML.

Aljibe de la Mar ina ${ }^{34}$ situado a pequeña distancia del almacén de vív eres, recogía parte de las aguas llovedizas que caían sobre la isla.Abovedado y de planta rectangular, su estructura es por tanto diferente al anterior, al necesitar filtrar

${ }^{33}$ Aljibe de la provisión contiguo al almacén de víveres. Sirve de depósito a el agua procedente de Málaga. Chafarinas 31 de agosto de 1868, el maestro mayor Lorenzo de Descallar. IHCM, Melilla, no 420.

${ }^{34}$ Aljibe de la marina situado a pequeña distancia del almacén de víeres. Recoge parte de las aguas llovedizas que caen en la isla. Chafarinas 31 de agosto de 1868, el maestro mayor Lorenzo de Descallar. El agua del aljibe no ha permitido terminar los dibujos. IHCM, Melilla, $n^{\circ} 418$. 
estas aguas que bajaban necesariamente impuras. Por ello contaba con tres recipientes independientes conectados entre sí que permitían limpiar el agua antes de pasar al depósito, y que funcionaban como purificador y decantador.

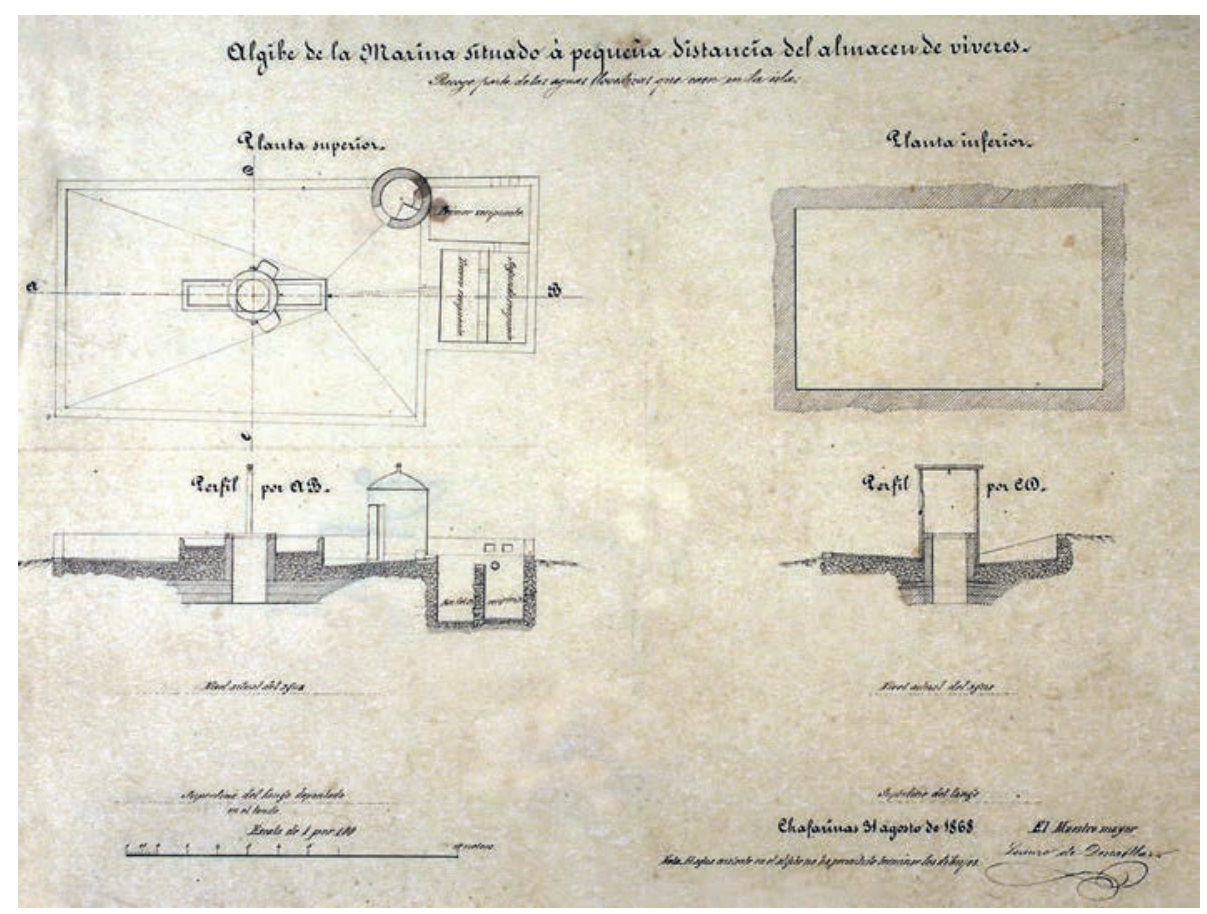

Aljibe de la marina situado a pequeña distancia del almacén de víveres. AIMML

De la misma tipología era el aljibe de la Bajada al Muelle, aunque no contamos con el plano de su estructura debía ser muy similar al anteriormente referido.

En 1868 ya existen al menos dos aljibes construidos en el interior de edificios, recogiendo por tanto el agua de lluvia que cá́ sobre la techumbre, lo que exigía que contaran con mecanismos para recogida de este agua llovediza: el del cuartel de Artillería y el del Presidio.

Aljibe del cuartel de Artillería ${ }^{35}$ estaba situado en la par te posterior de este mismo edificio, recogiendo las aguas llovedizas que caían en el tejado. De planta cuadrangular y cubierta abovedada.

${ }^{35}$ Aljibe del cuartel de artillería situado en la parte posterior de este mismo edificio, recoge las aguas llovedizas que caen en el tejado. Chafarinas 31 de agosto de 1868, el maestro mayor Lorenzo de Descallar.IHCM, Melilla, $n^{\circ} 419$. 


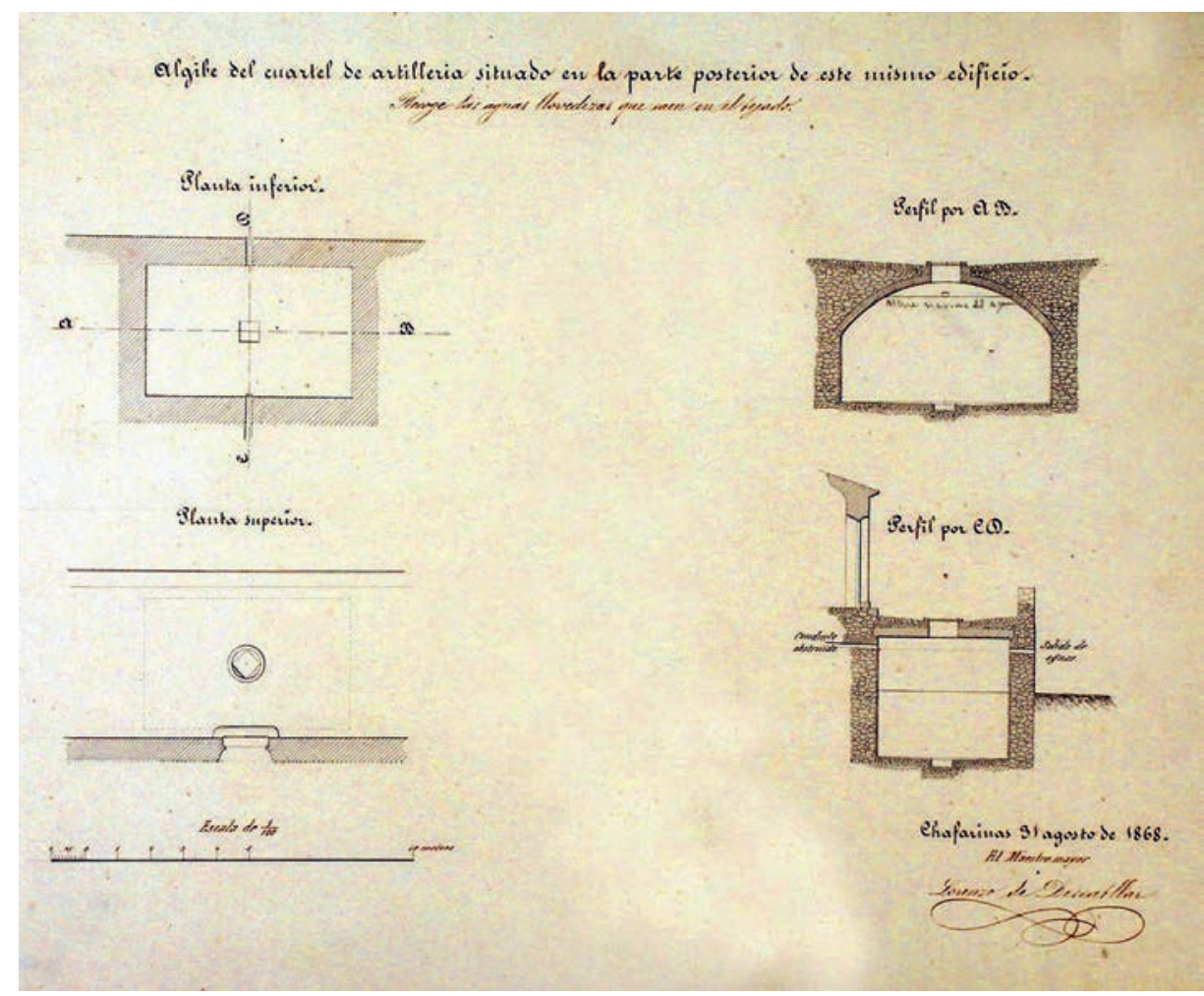

Aljibe del cuartel de artillería situado en la parte posterior de este mismo edificio. AIMML

Por último el aljibe del Presidio ${ }^{36}$ estaba situado en el centr o del patio de este edificio y recogía las aguas de lluvia. En este momento estaba sin r evestimiento su interior y solo principiados los conductos de entrada y salida.Era muy similar al anterior.

Las obras y mantenimiento de los aljibes construidos no cesaron. El 30 de junio de 1877 el ingeniero Aurelio Alcón, conectaba mediante tubería los aljibes de la Marina y el de la Bajada al Muelle, por un impor te de 820 pesetas y ese mismo año se reparaba el aljibe existente en el patio del cuartel de Artillería.

${ }^{36}$ Algibe del presidio situado en el centro del patio interior, recoge las aguas que caen en el edificio. Está sin revestimiento su interior y solo principiados los conductos de entrada y salida. Chafarinas 31 de agosto de 1868 , el maestro mayor Lorenzo de Descallar. IHCM, Melilla, $n^{\circ} 421$. 


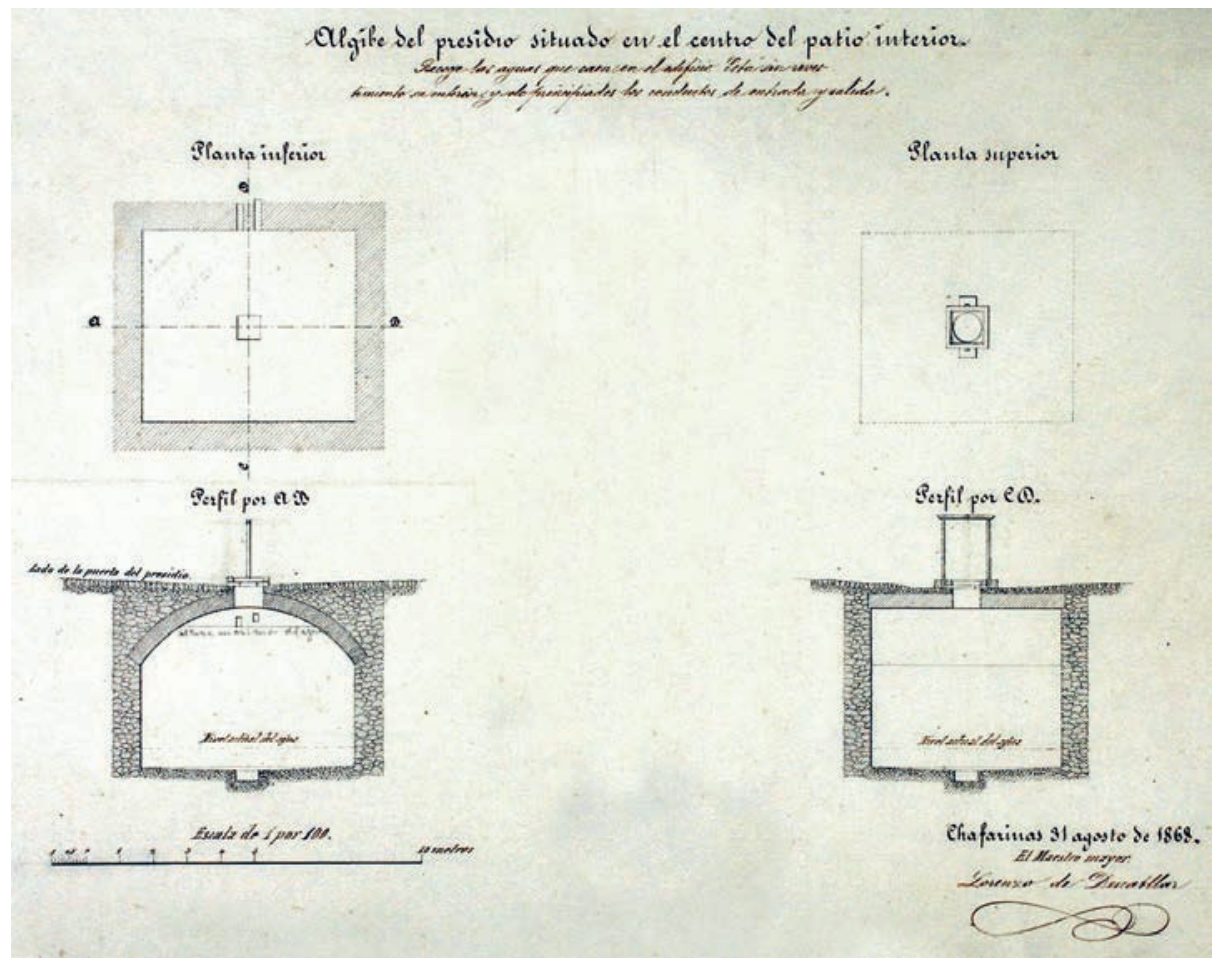

Algibe del presidio situado en el centro del patio interior. AIMML

En 1883 se plantea la reforma del aljibe de la Marina ${ }^{37}$. Existe un primer proyecto de Dionisio Delgado, un segundo de Juan Montero Esteban y uno final de Ricardo Vallespín. La reforma pretendía mejorar el sistema de captación del agua de escorrentía, su correcto depósito y la extracción mediante un sistema más moderno ${ }^{38}$.

${ }^{37}$ Proyecto de obras para la terminación de una cisterna. Melilla 13 de Mayo de 1883, Dionisio Delgado, Hoja Única. Melilla, 213. Proyecto de obras necesarias para la terminación de una cisterna, hoja única,Planta, cortes y Detalles. Melilla 31 de a gosto de 1883, Juan Montero Esteban, Examinado el ing eniero comandante Ricardo Vallespín. Proyecto de obras necesarias para la terminación de una cister na, Hoja Única, Planta, cortes y detalles. Melilla 31 de octubre de 1884, Ricardo deVallespín, Aprobado por R.O de 19 de enero de 1884.

${ }^{38}$ La reforma consiste en que la cisterna antigua pierde su cubier ta que se construye ahora con techumbre a dos aguas con cerchas de madera y tejas, se reforman los sistemas de captación del agua de la escorrentía en pequeñas arquetas situadas en dos de sus lados,y un sistema para la extracción del agua con una bomba de mano que se situaba en una pequeña habitación en uno de sus lados mayores. 


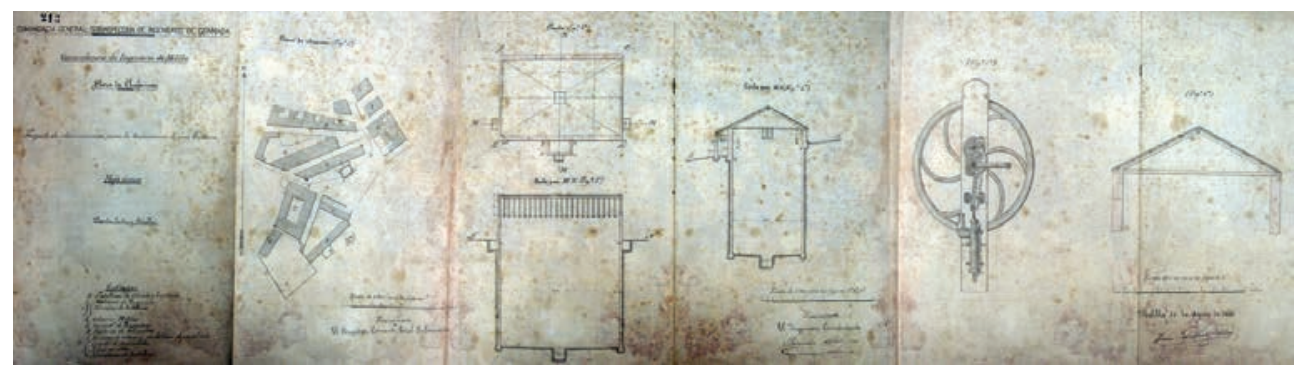

Proyecto de obras necesarias para la terminación de una cisterna, Melilla 31 de agosto de 1883, Juan Montero Esteban. AIMML

Posteriormente conocemos más proyectos de aljibes, demostrando la importancia que este tipo de construcción tiene en las islas Chafarinas. Algunos de ellos incluso destinados a fines agrícolas, caso del proyecto de aljibe a construir en el llamado Huerto del Vicario, en junio de 1904. En principio se trataba del proyecto de un maestro de obras, que termina refrendando posteriormente el ingeniero militar Alejandro Rodríguez Borlado ${ }^{39}$. Este ingeniero realiza un aljibe de 547 metros cúbicos, dos naves de tres metros de luz, dieciséis metros de longitud y seis metros de altura de cla ve. El proyecto lo ejecuta entre 1906 y 1907 y constaba de una cámara de decantación y una habitación donde se situaba el pozo para extraer el agua.
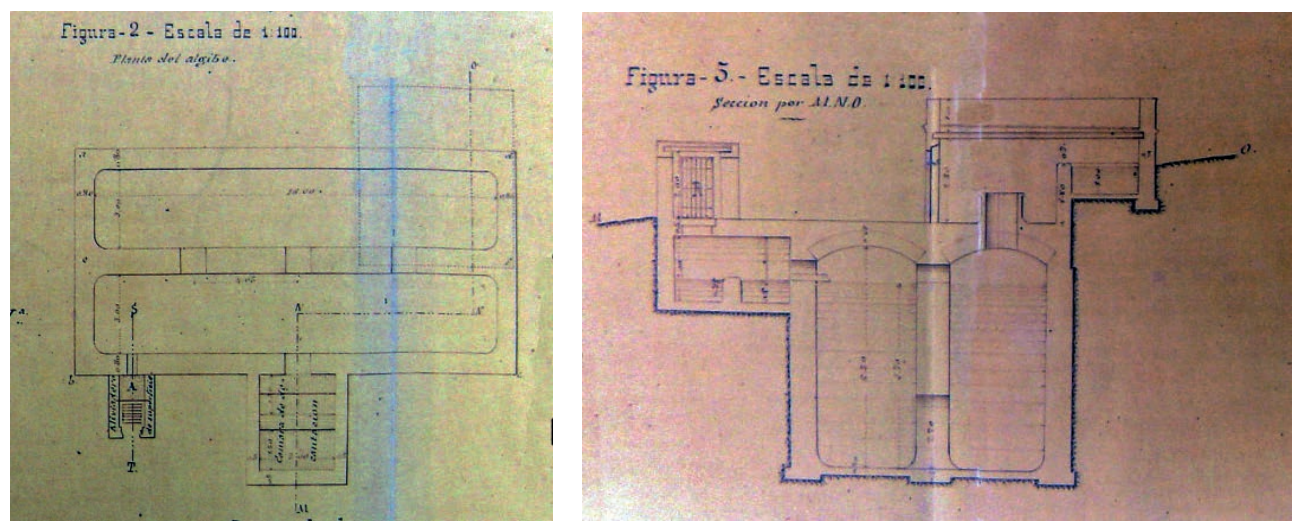

Proyecto de construcción de un aljibe. Sin fecha, sin autor, pero Alejandro Rodríguez Borlado. AIMML IHCM. $1023 / 3$.

${ }^{39}$ Proyecto de construcción de un algibe. Sin fecha, sin autor. 1023/3. 
Posteriormente se continuaron construyendo otros aljibes, hasta sumar once por toda la isla, debiendo hacer constar que el inicio de las obras del puerto requirió un gran esfuerzo en cuanto al agua necesaria para los trabajos y el abastecimiento de la población que había aumentado por entonces de una manera notable, lo que exigió incluso la instalación de maquinas destiladoras de agua del mar.

Un plano de 1918 nos ofrece una buena radiografía de este aumento en la capacidad de almacenamiento de agua en la isla, constando en esa fec ha once aljibes que se dividían en dos g rupos, según su titularidad: unos del Ejército y otros realizados por otras instituciones o por paticulares. En cuanto a su tipología, diez de ellos se nutrían de las aguas pluviales y uno era el aljibe que $\mathrm{r}$ ecibía el agua procedente de barco.

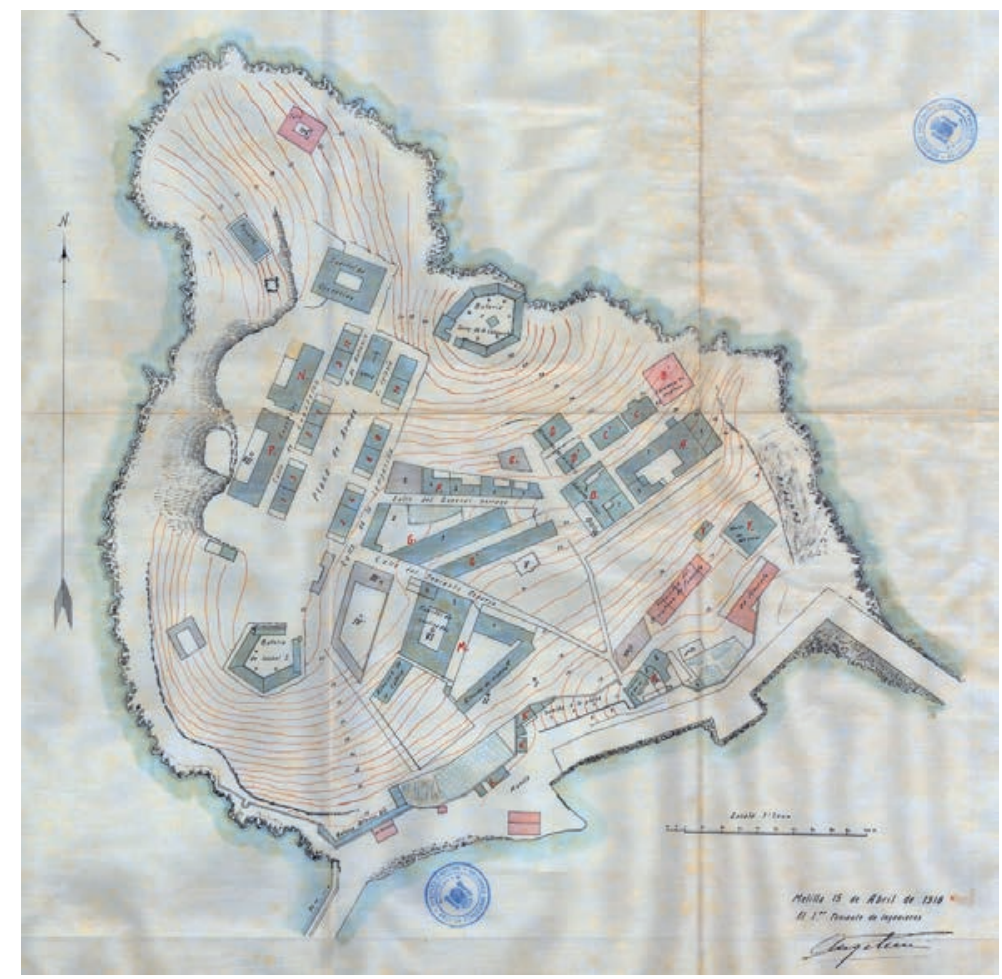

Plano del estado actual de la isla de Isabel II. Melilla, 15 de abril de 1918. AGMM.

La leyenda del plano nos indica los que pertenecían al Ejército que eran: I Bajada al Muelle, II de la Provisión, III entrada a la casa de Gobernador, IV otro 
en la entrada a la casa del Gobernador, V de la Marina, VI en el patio del cuartel de Confinados y VII en el patio del cuartel de Artillería.

Los que eran pr opiedad de par ticulares por su par te son: I' huerto del Vicario, II edificio particular frente al cuartel de Marina, III en el inter ior del edificio particular junto al cuar tel de Confinados y IV en el pa tio del edificio particular junto al cuartel de Confinados. Finalmente se refleja el V en el faro, propiedad de la Junta de Obras del Puerto. Todos estos aljibes estuvieron en uso y actualmente se conservan, la mayor parte de ellos abandonados y otros cegados, aunque se mantiene lo fundamental de su estructura.

\section{5-1886: las baterías}

A pesar de que se siguieron redactando interesantes proyectos de obras en las islas, como la reforma del edificio llamado cuartel de Operarios para transformarlo en hospital (ingeniero Emilio Cazorla y Prast ${ }^{40}$ ), resulta obvio que el proyecto de Aparici y Lombera no iba a lle varse a cabo, y que la pauta de no hacer nada volvía a apoderarse de la realidad, imponiendo sus ritmos.

Sin embargo, será el denominado conflicto de las Carolinas, en el que España pudo enfrentarse con Alemania, el que genere una nueva necesidad de fortificación y desde 1885 se suceden varios proyectos de nuevo artillado tanto en las islas Chafarinas como en Melilla.

El temor ante una posible intervención alemana en las Chafarinas, generó una nueva oleada de proyectos y la transformación de sus fortificaciones que se adaptaban a los trepidantes avances que en el ter reno de la ar tillería se habían producido en pocos años.

El 17 de septiembre de 1885 conocemos datos sobre la intención de instalar cuatro obuses en Chafarinas. Se trataba de cuatro obuses de avancarga H.R.S. de $21 \mathrm{~cm}$., modelo de 1870, a situar en la bđería de la Conquista.Por otra parte, el 29 de octubre se informaba sobre la adaptación en la fábrica Trubia de otros cañones de gran calibre destinados a Chafarinas.

${ }^{40}$ Plantas, perfil y vistas del edificio cuartel de operarios con el proyecto de obras de distribución interior para destinarlo a Hospital y pabellones necesar ios a sus dependencias formado por el capitán g raduado Teniente D. Emilio Cazorla y Prats. Melilla 10 de julio de 1871,Emilio Cazorla,VB Onofre Tojo, Aprobado, Madrid 6 de setiembre de 1871, copia de 29 de setiembre de 1871, Delineado por el teniente Francisco López y Carvayo. IHCM, Melilla, $n^{\circ} 404$. 


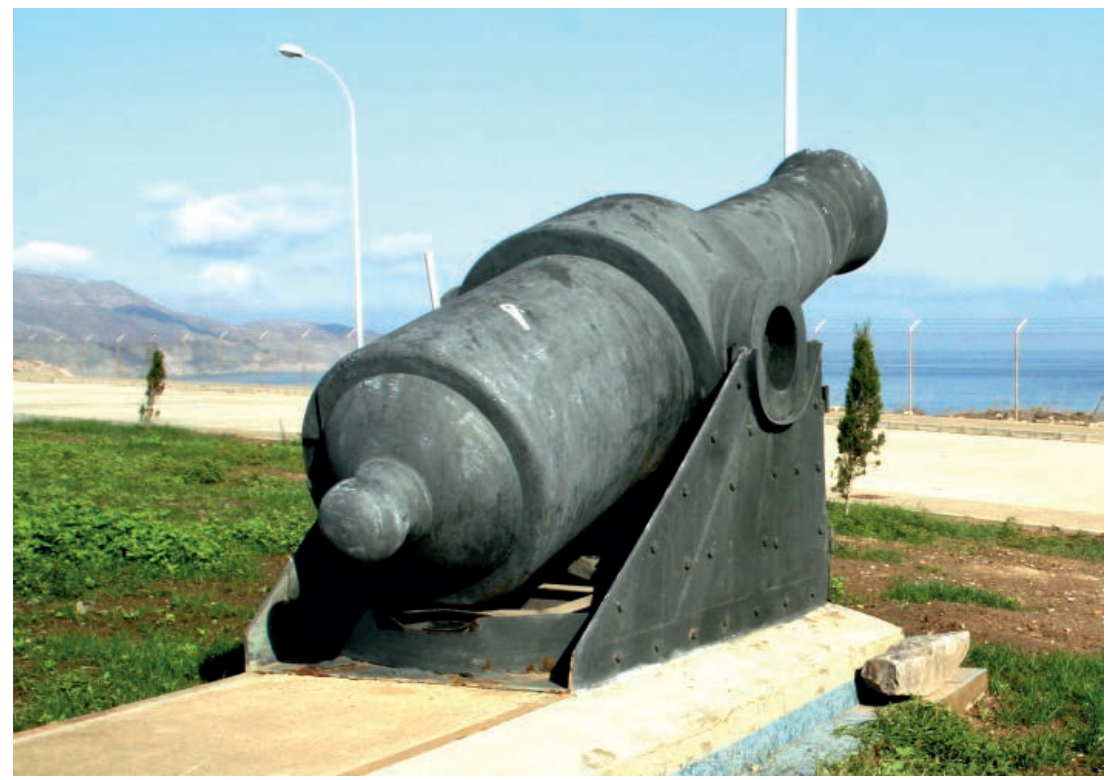

Obús procedente de Chafarinas situado actualmente en un acuartelamiento de Melilla.

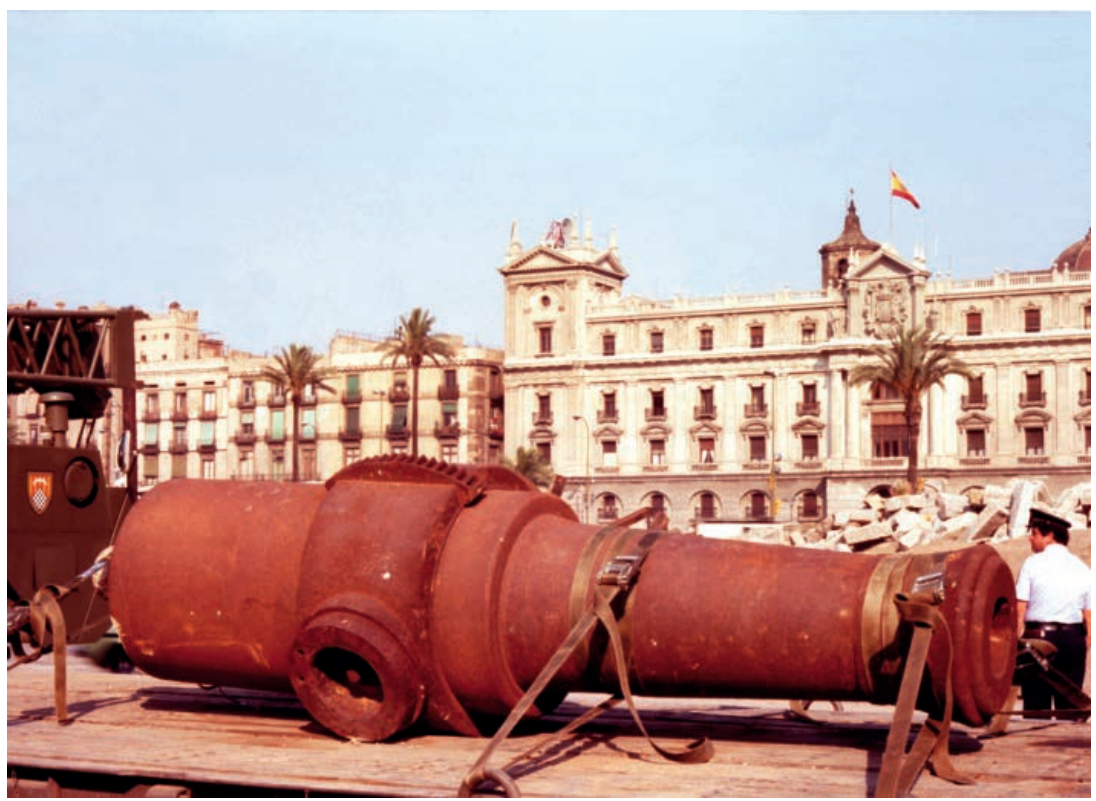

Obús de las islas Chafarinas. Fue regalado por el entonces comandante general de Melilla, D. José María

Bourgón a los veteranos catalanes que hicieron el servicio militar en Melilla. Actualmente está instaladoen el castillo de Cardona (Barcelona). Otros dos están en la entrada del Museo Militar de Sevilla. FCOML. 
Son dos cañones de costa Elorza ${ }^{41}$ de $24 \mathrm{~cm}$ modelo $1867 \mathrm{f}$ abricados en Trubia (piezas número 1 y número 2). Se trataba de dos piezas experimentales y por tanto únicas, la primera situada en montaje de marco bajo y emplazada en la batería de la Conquista, y la segunda en montaje de marco alto , situada en la batería de los Tristes. Estas piezas, de 13.840 kilos, permitían disparar un proyectil perforante de acero sólido de 144 kilos de peso a una velocidad inicial de 320 metros por segundo, capaz de atravesar $15 \mathrm{~cm}$ de blindaje a 1.000 metros.

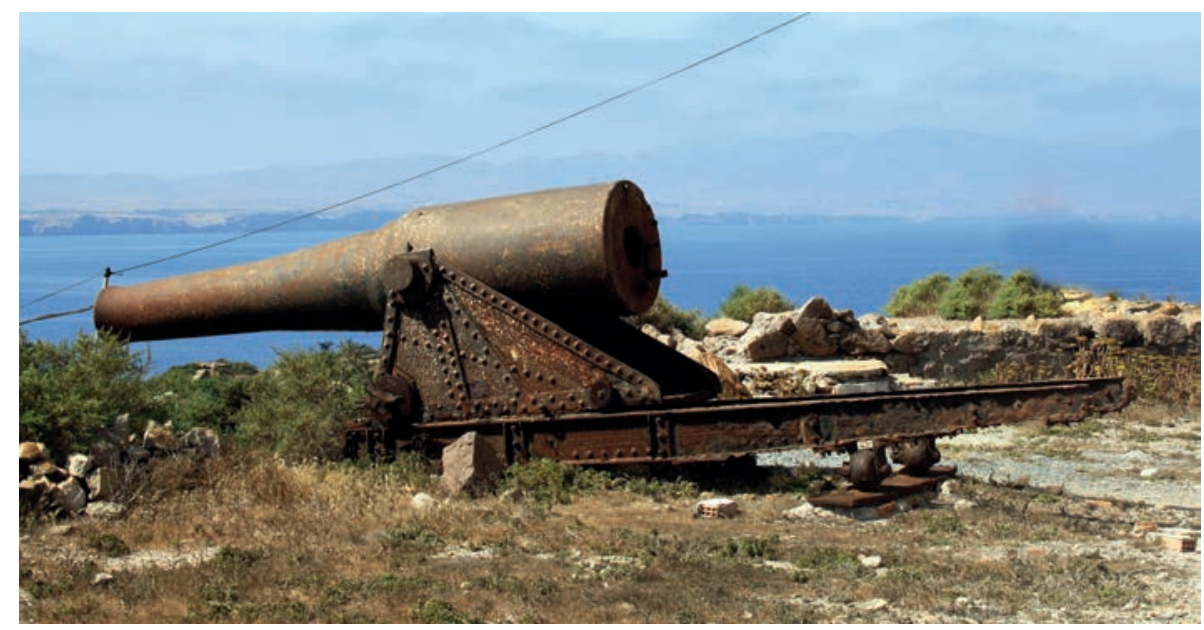

Elorza de $24 \mathrm{~cm}, n^{\circ} 1$, sobre montaje bajo en la batería de la Conquista.

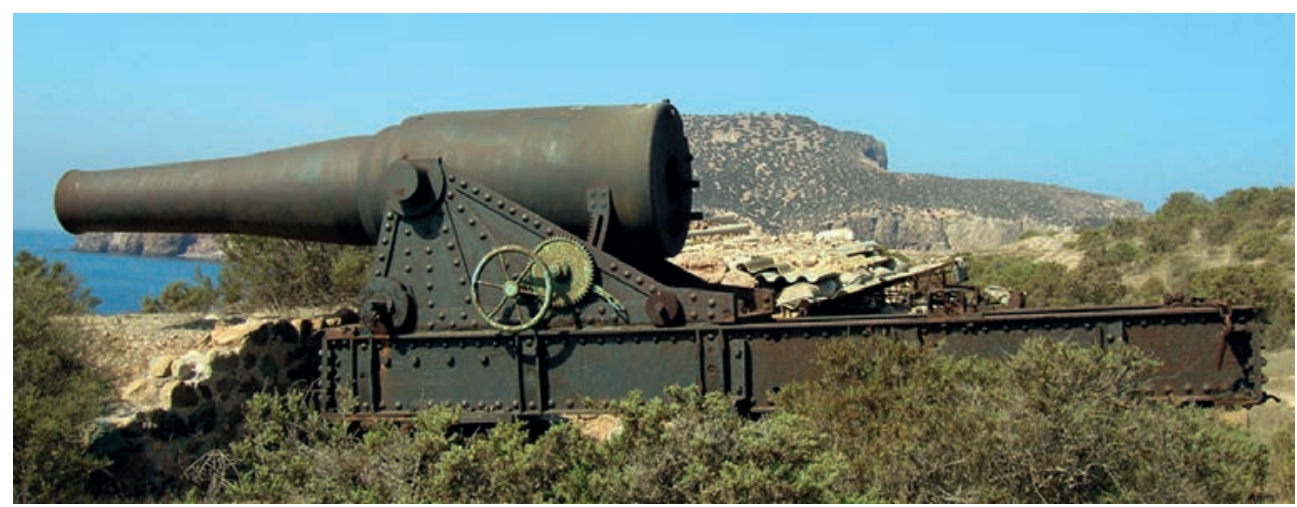

Elorza de $24 \mathrm{~cm}, \mathrm{n}^{\circ}$ 2, con montante alto en la batería de los Tristes.

${ }^{41}$ MORTERA PÉREZ, Artemio (2000). «S.O.S. Museos». Historia Militar, julio 2000; p. 239-240. 
El montaje lo realizó una compañía de ingenieros desplazada a la isla expresamente para ejecutar este trabaja Lo primero que se realizó fueron las obras de fábrica y luego las piezas fuer on llevadas en lanchones y remolcados por el vapor Numancia, que era el barco correo de los presidios.

En cuanto a las obras de fábr ica llevadas a cabo las conocemos m uy bien gracias a los proyectos realizados entre 1885 y 1886.

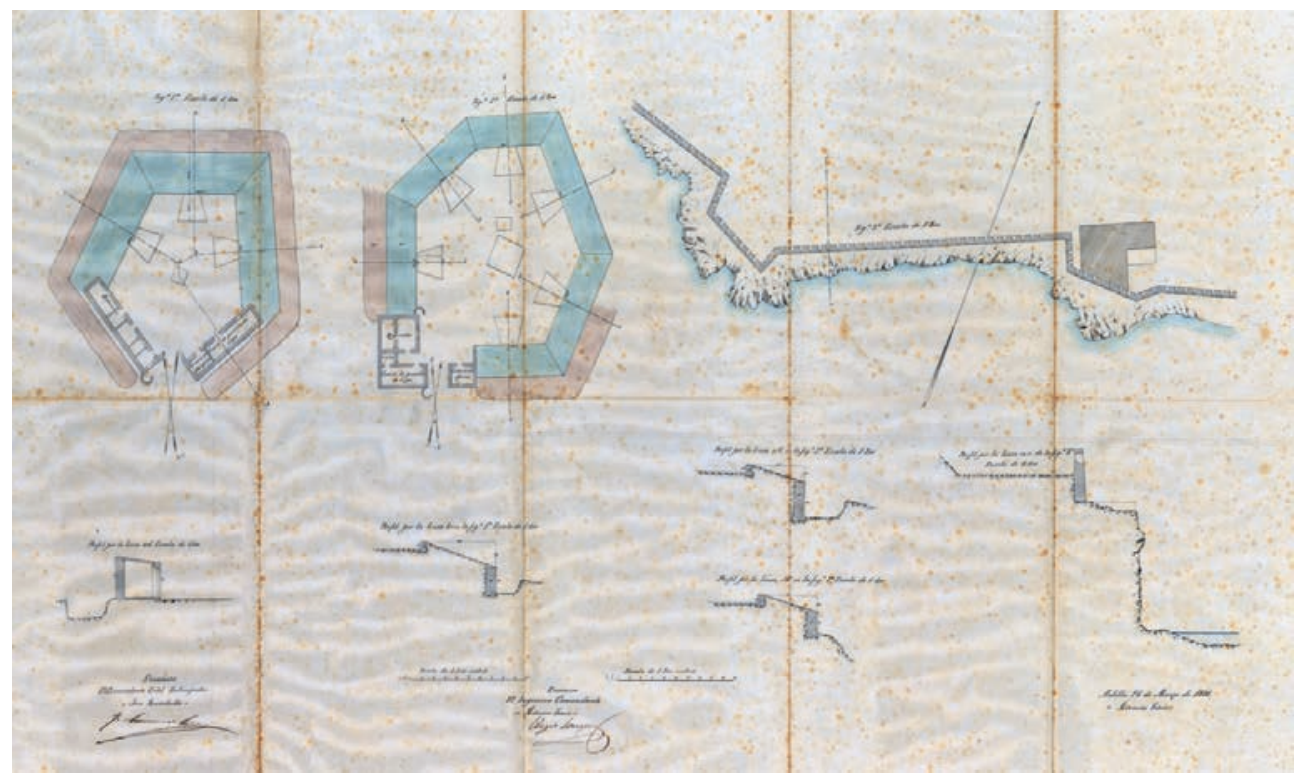

Proyecto de obras para el artillado rápido, Melilla, 25 de marzo de 1886. AGMM.

Fondo África R821 15.2. Manifiesta el estado en el que se encontraban las baterías antes de la reforma.

En un plano de $1886^{42}$ se refleja el estado en el que se encontraban las dos baterías de la Conquista y de Isabel II (anter ior de Isabel I), así como el sector de muralla aspillerado donde se proponía construir la nueva batería, al Sur de la isla.

${ }^{42}$ Proyecto de obras para el artillado rápido, Melilla, 25 de marzo de 1886. AGMM. fondo África R821/5.2 


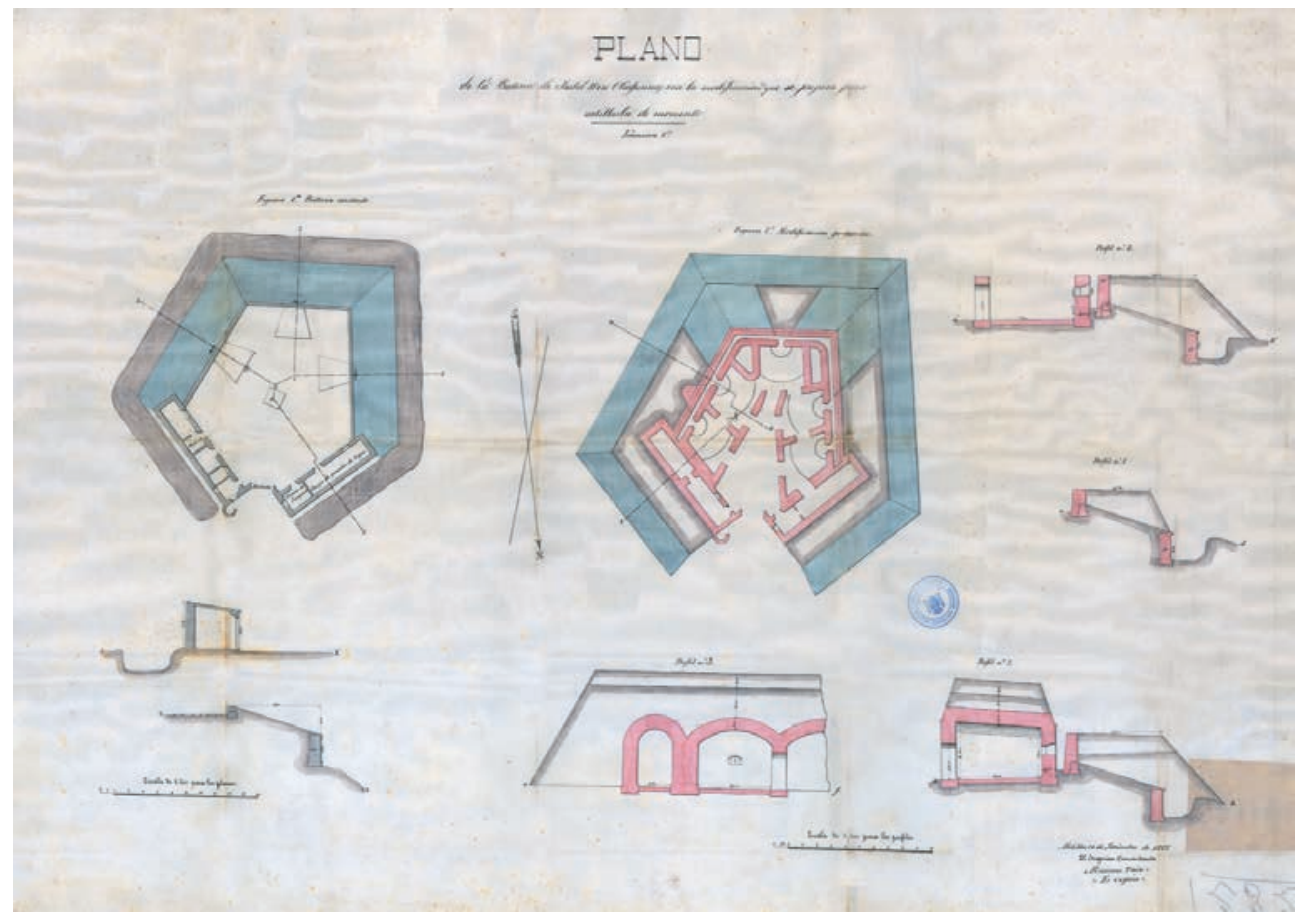

Plano de la batería de la Conquista en Chafarinas con la modificación que se propone para artillarla, 24 de septiembre de 1885, Ramón Taix. AGMM. Fondo África R821/5.2.

La batería de la Conquista ${ }^{43}$, disponía de una torre en su interior que figura como faro, y unos cuartos en la entrada que servían de cuerpos de guardia y cuarto del oficial. Disponía de seis cañoneras a barbeta, y en los perfiles consta el espesor de los parapetos que es de unos cinco metros, sin caponeras. Un primer proyecto del ingeniero Ramón Taix pretendía transformarla en un fuerte acasamatado, construir siete caponeras cubiertas con bóvedas y un parapeto mucho mayor.

Por su parte, la batería de Isabel II ${ }^{44}$ albergaba tres piezas y se proyectaba para cinco; aunque de menores proporciones que la anterior, Ramón Taix planteaba la misma idea de fuerte acasamatado.

43 1885. Plano de la batería de la Conquista en Chafarinas con la modificación que se propone para artillarla de momento, lámina 1. Melilla 24 de septiembre de 1885, Ramón Taix. AGMM. fondo África R821/5.2.

${ }^{44}$ 1885. Plano de la batería de Isabel II en Chafar inas con la modificación que se propone para artillarla de momento, lámina 1. Melilla 24 de septiembre de 1885, Ramón Taix. AGMM. fondo África $R 821 / 5.2$ 


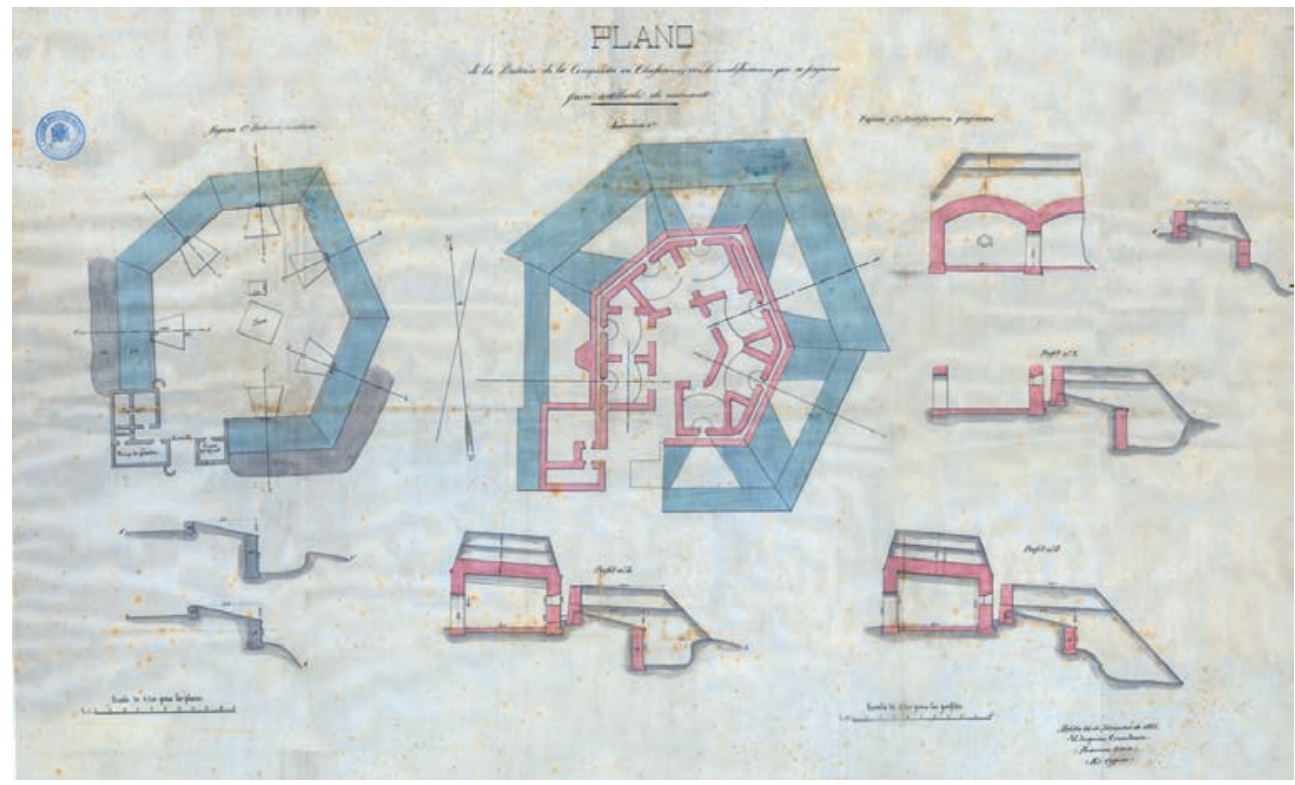

Plano de la batería de Isabel II en Chafarinas con la modificación que se propone para artillarla, 24 de septiembre de 1885, Ramón Taix. AGMM. Fondo África R821/5.2.

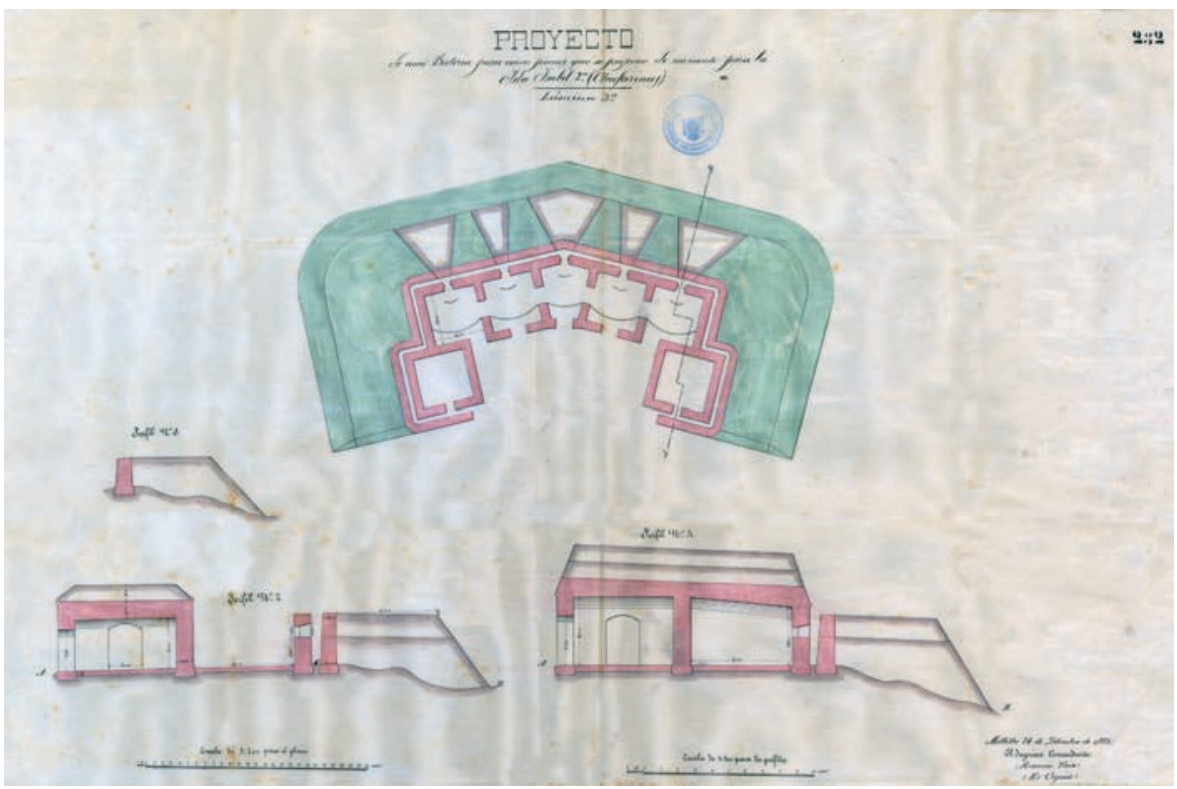

Proyecto de una batería para cinco piezas para la isla Isabel $2^{a} 24$ de septiembre de 1885, Ramón Taix. AGMM. Fondo África R821/5.2 
Por su parte en el Sur de la isla se proyectaba una batería para cinco piezas ${ }^{45}$ de planta ligeramente pentagonal, que finalmente no se realizó con esta forma, y que se llamaría de los Tristes.

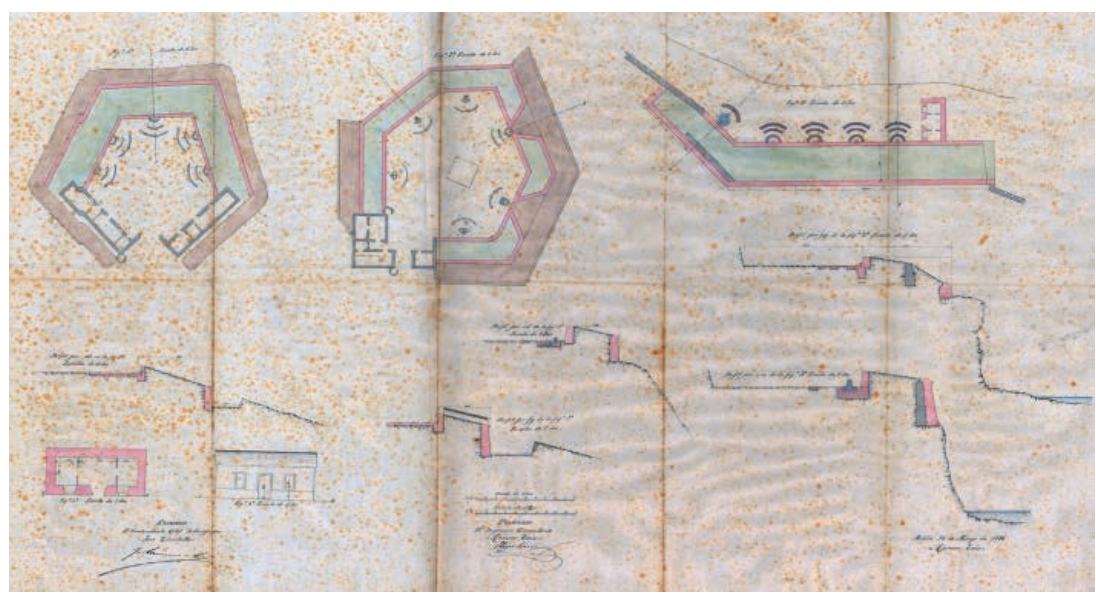

188625 de marzo proyecto de obras para el artillado rápido en las islas Chafarinas, AGMM, fondo África R821/5.2.

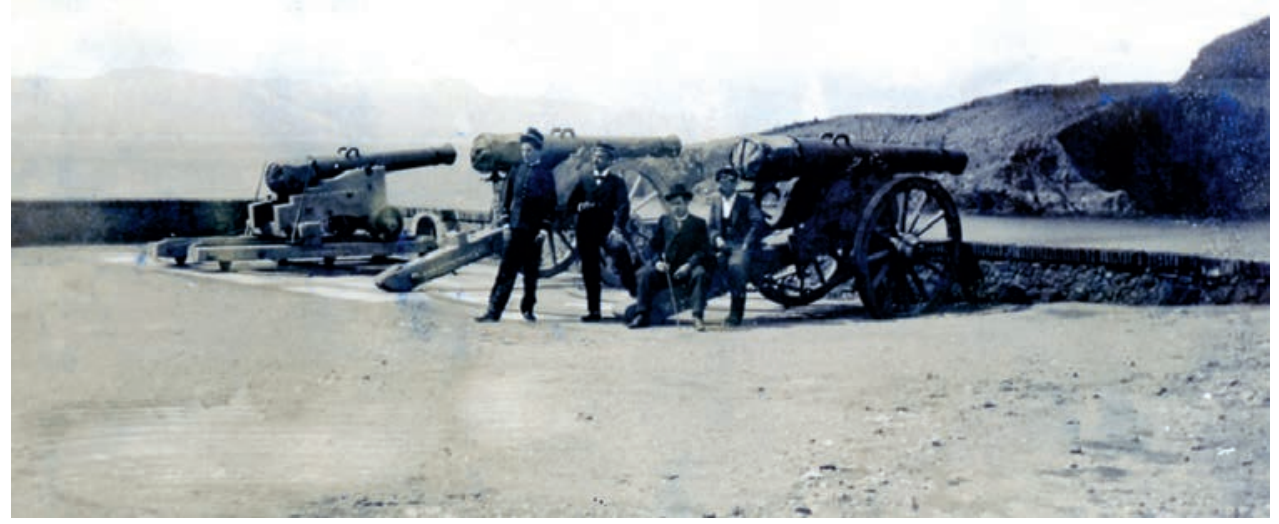

Vista de la batería de Isabel II con varias piezas artilleras en dirección a la isla del Congreso, finales del siglo XIX. FCOML.

45 1885. Proyecto de una ba tería para cinco piezas que se propone de momento par a la isla Isabel $2^{a}$ (Chafarinas). Lámina 3. Melilla, 24 de septiembre de 1885, Ramón Taix. AGMM. fondo África R821/5.2 


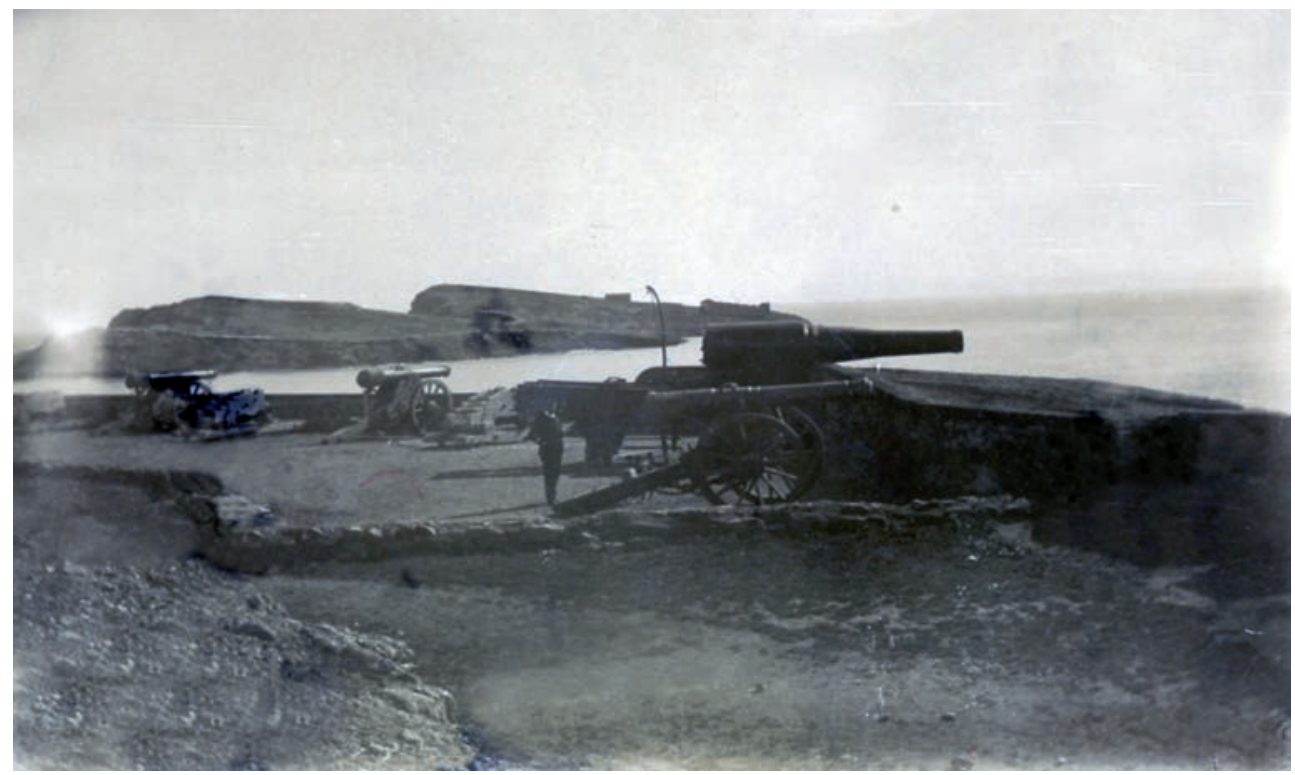

Batería de los Tristes a finales del siglo XIX. FCOML.

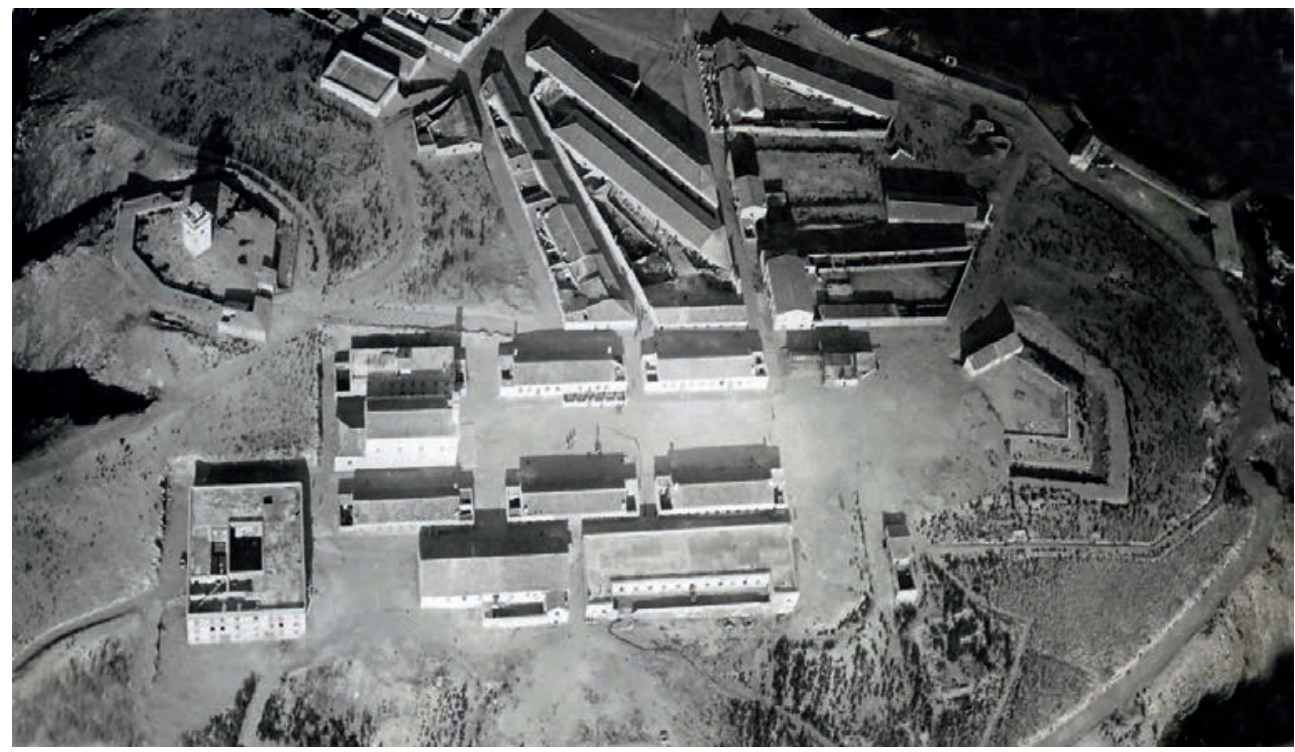

Vista aérea de la isla de Isabel II. A la izquierda (Norte) la batería de la Conquista, a la derecha (Sur) la batería de Isabel II y la de los Tristes, derecha arriba. Hacia 1923. 


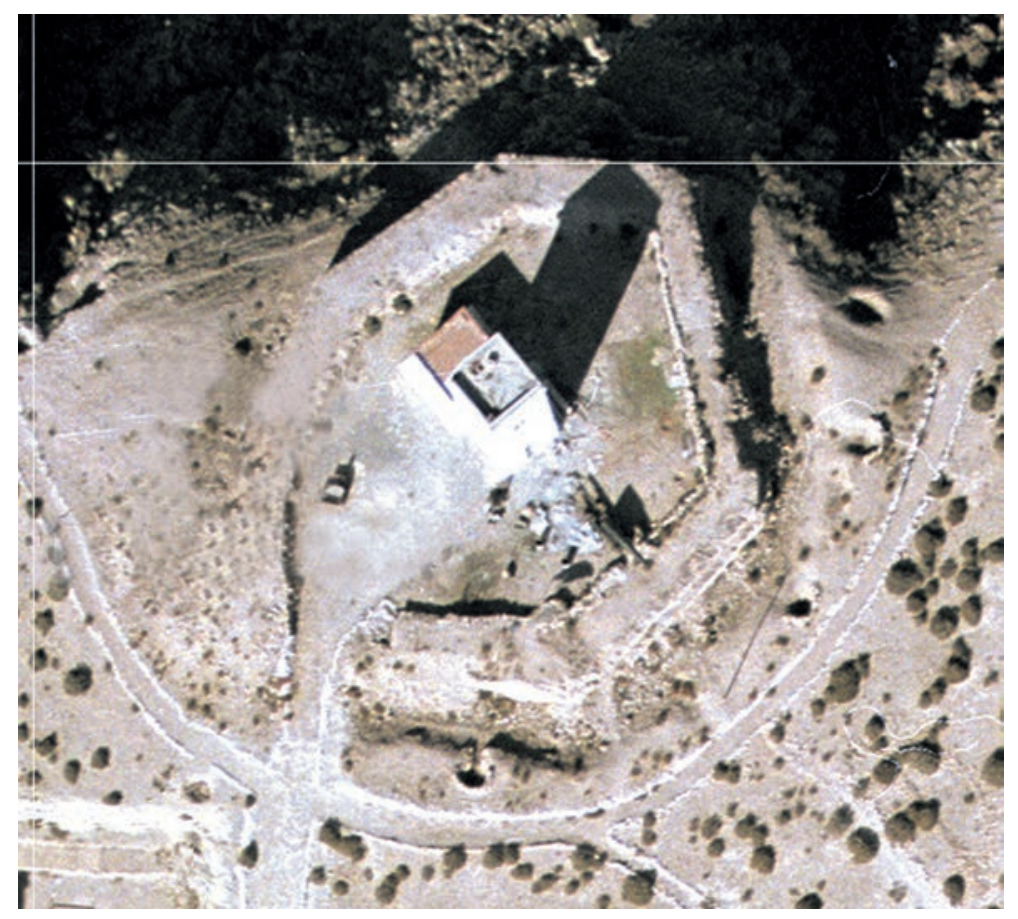

Batería de la Conquista, actual.

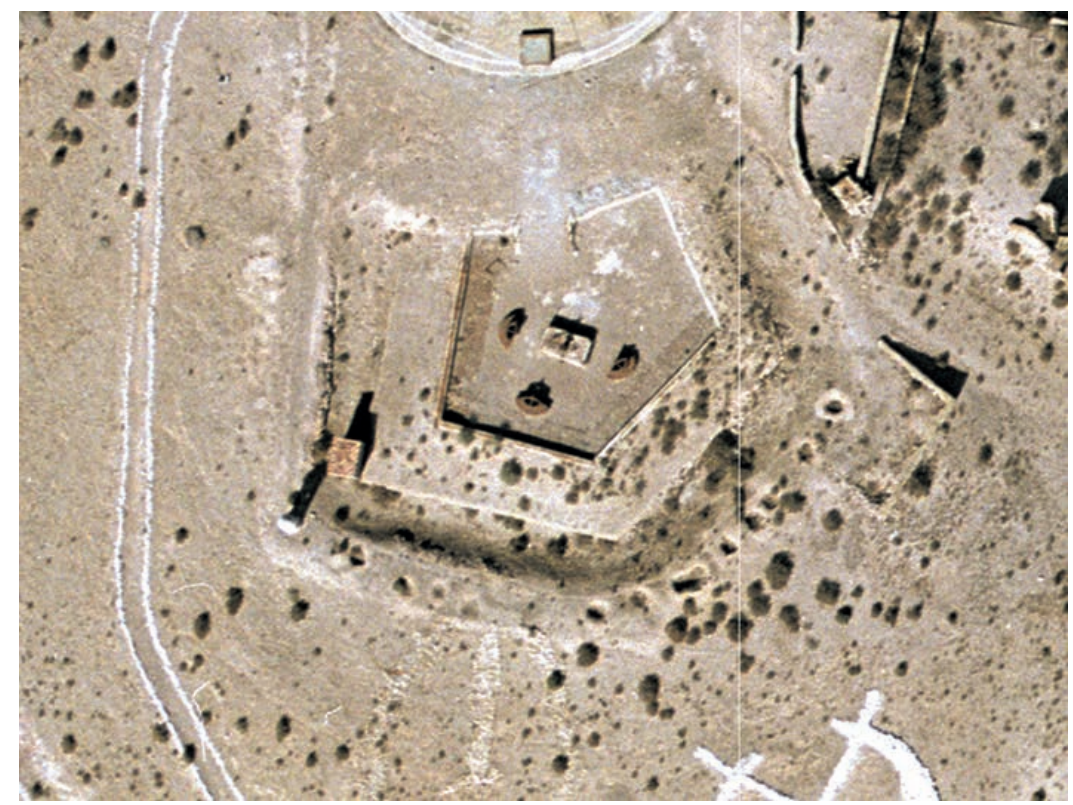

Batería de Isabel II, actual, en la que se observan todavía los asentamientos artilleros. 
Finalmente estos proyectos fueron reformados por el mismo ingenier o, simplificando su tipología (y con ello economizando gastos). El proyecto de artillado que se ejecuta definitivamente se refleja en un plano de $1886^{46}$. En él se aprecia la modificación de la batería de Isabel II adaptándola como batería para cinco piezas a barbeta sin casamata. La Conquista por su parte contaría con seis baterías, dos de ellas con aber tura en el parapeto. Finalmente la planta de la batería de los Tristes dispondría de cinco piezas, fortaleciéndose el muro externo de fábrica.Y este es el estado en el que todas estas obras nos han llegado hasta nuestros días, perdiéndose la última opor tunidad de reformar radicalmente el viejo sistema defensivo de las islas.

El interés de los ingenieros militares por encontrar la disposición perfecta de la defensa, nos ha legado otros tanteos de for tificación, encontrándonos con un último proyecto que refleja todavía la importancia del sistema de for tificación poligonal basado en caponeras flanqueantes. Se trata de un pr oyecto para transformar la batería de la Conquista en un fuerte acasamatado, y que no llegó a realizarse.

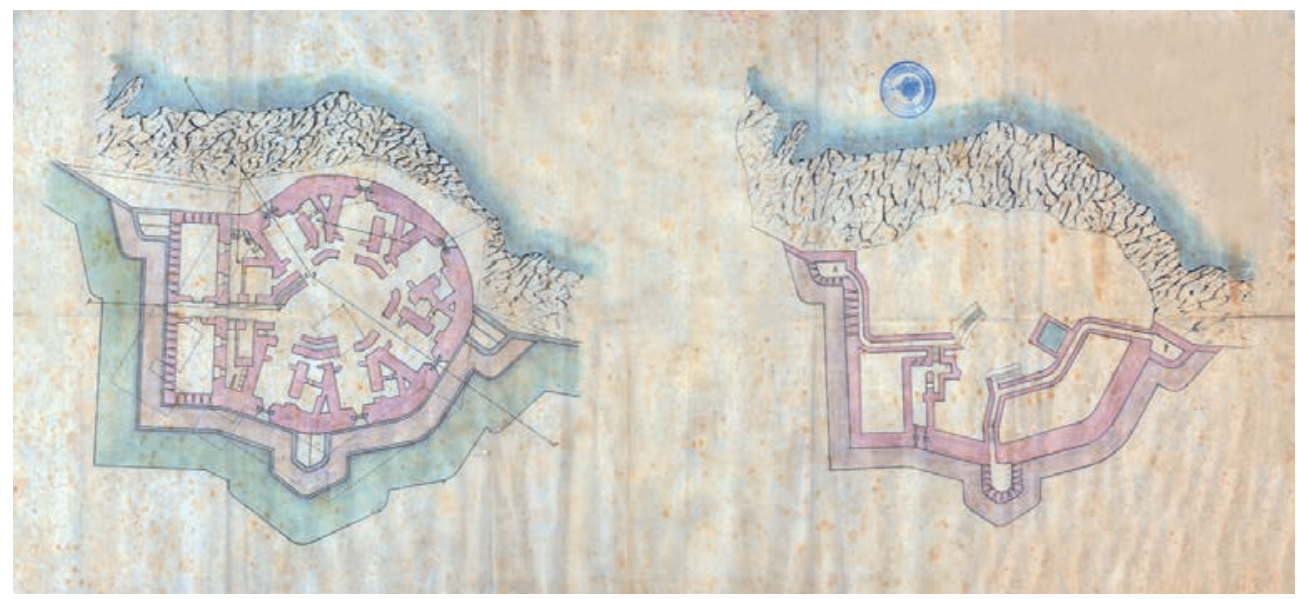

AGMM, África, 1680-7. Sin fecha ni referencia. Corresponde a un tanteo de fuerte a construir en la batería de la Conquista.

${ }^{46} 188625$ de marzo proyecto de obras para el artillado rápido en las islas Chafarinas, AGMM, fondo África R821/5.2, Ramón Taix. Otro en: R825.2 con Eligio Sousa y Ramón Taix. AGMM. fondo África R821/5.2. 
Finalmente la batería mantuvo la misma tipología con la que se había construido en 1848, con las modificaciones importantes del artillado de 1886, y en ese estado, con los evidentes deterioros generados por el paso del tiempo en un lugar tan expuesto a temporales y vientos, ha quedado hasta nuestros días.

\section{Algunas referencias posteriores. Conclusiones}

Los momentos finales del siglo XIX y principios del XX son paradójicos. Por un lado es el periodo en el que las islas tienen mayor importancia, desempeñaron un papel relevante y tuvieron mayor población, pero siempre se cumple el axioma de que para poder desarrollarse una población nueva, tiene que destruirse u olvidarse sus murallas.

Chafarinas comienza el despegue que parecía iba a permitir su conversión en una población importante y en todos los proyectos y planos se observa como la cuestión de la fortificación pasa a un segundo término.

El poder español, la penetración de las tropas españolas en Marruecos y el control marítimo de su armada, hacían imposible pensar en un ataque a unas islas que lentamente se estaban quedando v aradas, sin darse cuenta, en uno de los meandros caprichosos de la historia. Ya nunca volvieron a tener tanta importancia y el languidecimiento de la población civil, determina que vuelvan a convertirse en un puesto exclusiamente militar, cuyos planes de defensa y fortificación se vuelven a hacer necesarios, adaptados obviamente a otros criterios.

En varios planos de finales del XIX y pr imeros años del veinte ya vemos como se había congelado este sistema defensiø, e incluso figuran en ruinas algunos de sus elementos principales.

1905 es la fecha que cierra este trabajo, el final de una forma de entender las defensas de las islas . Ese año se $r$ ealiza el Proyecto de mejora del puer to natural de las islas Chafarinas, por el ingeniero de caminos Manuel Becerra.También en ese momento el pr estigioso ingeniero militar Emilio Her rera ${ }^{47}$ sitúa varios proyectores de luz en las islas para mejorar las posibilidades de tiro, pero el proyecto en sí mismo ya representa la decadencia absoluta y el abandono de los sistemas fortificados poligonales o de flanqueo que hemos rflejado a lo largo de este capítulo. Todos los elementos que se conser van de esa época, debemos considerarlos ya plenamente como arqueología militar.

\footnotetext{
${ }^{47}$ AGMM, R173.
} 